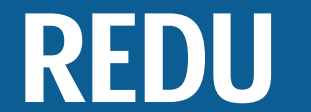

Revista de Docencia Universitaria

Vol $10 \mathbf{N}^{0} 1$

\section{HISTORIA DE VDA}

\section{Marycruz Arcos Vargas}

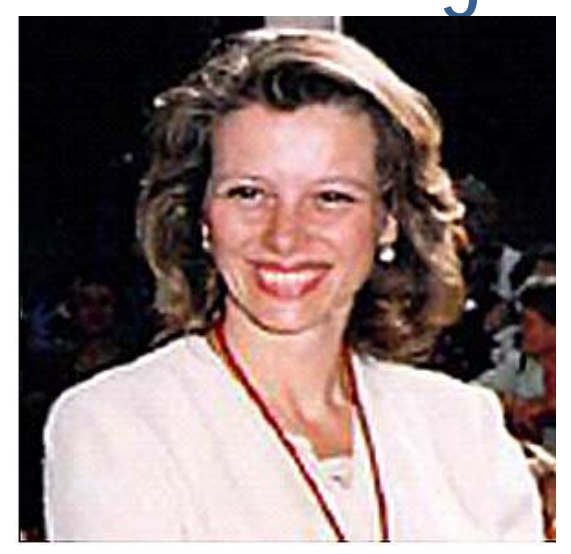

Profesora del Dpto. de Derecho Administrativo y Derecho Internacional Público y Relaciones Internacionales Universidad de Sevilla 



\title{
Internacionalización de la universidad: Abrir ventanas al conocimiento y al mundo profesional
}

\author{
Internationalization of the university: \\ To open windows for the knowledge and for the professional world
}

\author{
Araceli Estebaranz García \\ Miguel Ángel Ballesteros Moscosio \\ Universidad de Sevilla, España
}

\section{Resumen}

El proceso de Internacionalización de la Universidad de Sevilla, uno de los retos de futuro del Rectorado actual, en sus orígenes va ligado inexorablemente a la historia de vida académica y profesional de la profesora Marycruz Arcos Vargas ${ }^{1}$ y a su liderazgo como Vicerrectora de Relaciones Institucionales, Internacionales y Extensión Cultural. Por eso la hemos elegido como ejemplo del impacto que las acciones personales calificables como buenas prácticas tienen en la vida de la institución universitaria y en el éxito de sus funciones, también formativas. Su experiencia profesional dentro del Derecho Internacional integra funciones de docencia, investigación y gestión a lo largo de 25 años, en su Universidad, a la que ama profundamente.

Palabras clave: Enseñanza Universitaria; Formación europea; Cooperación Internacional; Compromiso cultural; Compromiso Institucional.

\section{Summary}

The process of Internationalization of the University of Seville, one of the challenges of future of the current Rectorate, in its origins is tied inexorably to the history of the academic and professional life of Marycruz Arcos Vargas and to her leadership like Vice-rector of Institutional and International Relations, and Cultural Extension. That's why we have chosen her as an example of the impact that the personal

\footnotetext{
${ }^{1}$ La narración sobre la historia de vida y aprendizaje profesional de Marycruz Arcos, se basa en los datos objetivos obtenidos de la documentación de la propia Universidad de Sevilla, algunos disponibles en la web; de las observaciones y contactos que los autores del relato han tenido con ella en Conferencias y Actos institucionales o culturales, de tres entrevistas realizadas en 2008, 2010, y 2012. El texto integra datos objetivos, la visión subjetiva de la persona entrevistada -que muestra utilizando en cursiva frases personales significativas y los textos en vídeo-, y la interpretación desde la teoría didáctica y organizativa. Para visionar los fragmentos de vídeo pulse sobre el icono abrirá su navegador en la dirección de Youtube a la que se vinculan, permaneciendo abierto a un tiempo Acrobat Reader.
} 
actions qualifying as good practices have in the life of the university institution and in the success of its functions, also formative. Her professional experience inside the International Law integrates functions of teaching, investigation and management throughout 25 years in her University, whom she loves deeply.

Key words: University Education; European Formation; International Cooperation; Cultural Commitment; Institutional Commitment.

\section{Yo me meto en todos los charcos}

Algunas personas tienen la sencillez como parte estructural de su personalidad. No pueden despojarse de esa cualidad aunque quisieran...

... Yo me mantuve en silencio, abrumado por haber descubierto otra estrella en el firmamento de mi vida.

(Sankar, Chowringhee, 2011: 491, 449).

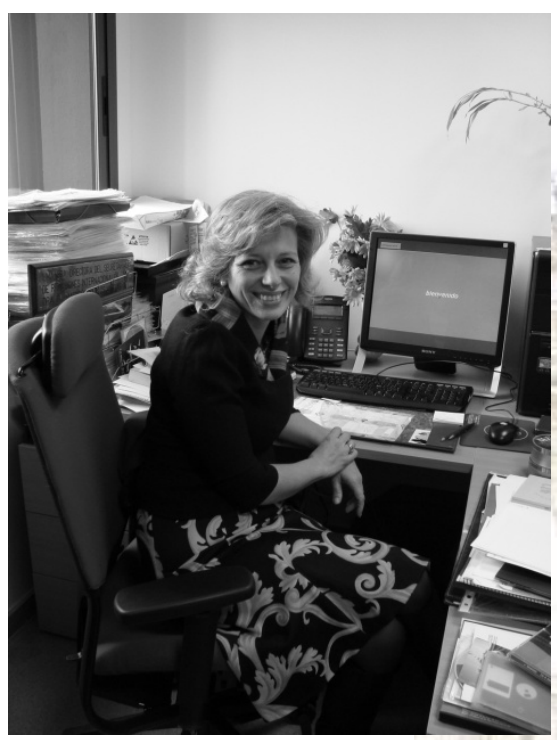

Doctora en Derecho Internacional (1994).

Profesora Titular del Departamento de Derecho Administrativo y Derecho Internacional Público y Relaciones Internacionales de la Universidad de Sevilla (1997).

Pertenece al Grupo de Investigación: Derechos Humanos.

Directora del Secretariado de Relaciones Internacionales desde su creación (2000-2003).

Vicerrectora de Relaciones Institucionales, Internacionales y Extensión Cultural (2003-2008). Actualmente Directora del Centro de Documentación Europea (desde 2008).

Casada. Tiene un hijo de 15 años y dos hijas de 12 y 9 años.

\section{La persona}

Hemos elegido a Marycruz entre muchos profesores excelentes, por su contribución a la innovación en la Universidad, impulsando su apertura a las relaciones europeas, a las relaciones institucionales y el fomento de la Cultura, germen de las acciones de Responsabilidad Social Corporativa que hoy se desarrollan en la Universidad de Sevilla; el ejercicio de la función directiva con características claramente femeninas, de atención, disponibilidad para recibir y escuchar a las personas y buscar soluciones, trabajo constante, ilusión, y resolución; la práctica de la conciliación entre la vida profesional y la familiar; y la gran motivación y entusiasmo en su función docente. Son valores importantes, que pueden iluminar a diferentes profesores universitarios como la estrella de Sankar -al referirse poéticamente a una mujer-, precisamente en su sencillez. 


\section{Vivir la cultura. Educar participando en la sociedad}

Los niños se presentan solos; no es preciso hacerles el artículo porque muestran bien pronto quiénes son. Pero los niños también presentan a sus padres. Sobre todo describen y explican la vida familiar a través de sus comportamientos. Por eso hemos elegido dos anécdotas de las Navidades de 2008-2009 para presentar a Marycruz.

El día 2 de enero asistía a un Concierto de Navidad de órgano y trompeta con su hijo de 11 años y sus dos hijas de 9 y 6 años. No es la única madre que lleva a sus hijos, pero sí la que piensa disfrutar de la música con los tres y de esas edades. Se coloca cerca de los intérpretes porque su hijo quiere ver cómo se toca un órgano de 4 teclados y pedalero. Enseguida el niño se va a la primera fila. Las niñas permanecen a su lado. La más mayor se cambia de fila hacia la mitad del concierto. La más pequeña oye las últimas piezas en brazos de su madre. No hacen ruido, y su madre entiende la necesidad de acomodarse de cada uno de sus hijos, en un espacio -la Catedral-, que permite el movimiento sin molestar, además de ser una actividad para la que el auditorio es menos exigente porque "no ha tenido que pagar una entrada"

Saben dónde están, disfrutan en familia de un tipo de música muy valioso y formativo, mientras van creciendo su conocimiento y su gusto por ella y el autocontrol de su comportamiento en los espacios públicos. La madre les ha ofrecido la oportunidad de compartir una de sus aficiones, con normas pero con flexibilidad y sin exigencias disciplinarias que interfieran en una situación de aprendizaje estupenda. La naturalidad con la que se comportan habla de aprendizajes vivenciales.

El 5 de enero vuelve a aparecer la mujer que disfruta de la vida cultural de su ciudad, y que muestra sus competencias para la resolución de conflictos que necesitan la decisión inmediata en los espacios públicos. Esperando pasar la Cabalgata de Reyes en la Plaza de San Pedro, cargada de bolsas de caramelos para reponer las existencias de su hija mayor, aparece una pandilla de canis, "pero canis, canis"... Y la abordaron. Su respuesta rápida muestra claramente su capacidad de decisión, su resolución y su confianza en las personas, pero sobre todo su capacidad de negociación y su confianza en sí misma. No tiene que pedir ayuda a la cantidad de gente que la rodea. Negocia directamente con el grupo, aprovechando su necesidad de ayuda y su estatura; ella no es muy alta: "Sí, yo os voy a dar caramelos, pero cuando pase la carroza de mi hija me ayudáis a tirarle las bolsas para que lleguen a ella". Su respuesta fue bien positiva: "Ningún problema. Fue una ayuda porque era un objetivo difícil dada la altura de las carrozas..."

Ésa es su percepción de los hechos y su tono, sencillo y elegante, como lo es su presencia y su estilo personal, aunque el abrigo, o el traje que lleve puesto los haya conseguido a un precio impensable porque le gusta regatear o comprar en rebajas en los contextos adecuados.

Cuando comenta la participación de sus hijos en la vida cultural lo hace con la mayor naturalidad. Pero es una magnífica forma de que los niños vayan echando raíces, integrándose en la forma de vida de su ciudad y valorándola, y, por lo mismo, respetándola, porque nadie maltrata lo que ama; una importante forma de educación ciudadana que ocurre sencillamente al compás de la sucesión de fiestas compartidas, donde van rotando los papeles que cada persona, niño y niña, mayores y pequeños, 
desempeña en ellas. Una forma de ir aprendiendo que ahora "me toca a mí repartir caramelos", ser generoso con las otras personas. Un aprendizaje simbólico de la responsabilidad social. Y apenas alude al esfuerzo y al tiempo que le ha ocupado la preparación de su hija para "salir en la Cabalgata". Lo primordial es el goce que proporciona a la niña, y que tiene su momento; no vale posponerlo para otro año. Es disfrutar de ser una madre.

Ahora tiene 49 años. Está casada. Su marido es empresario. Ambos tipos de trabajo, la Universidad y la Empresa, son muy exigentes, absorbentes de cualquier cantidad de tiempo, atención y esfuerzo. Pero se puede sostener una familia estructurada, con motivación, con una relación idílica, con la autonomía de ambos para organizarse su tiempo, y con el compromiso de suplirse en las funciones familiares:

Durante la época de Vicerrectorado, yo he trabajado el $80 \%$ de los fines de semana. Pero si yo no estoy en casa está su padre.

Evidentemente, mucho de su trabajo consistía en representar a la Universidad en diferentes tipos de actos.

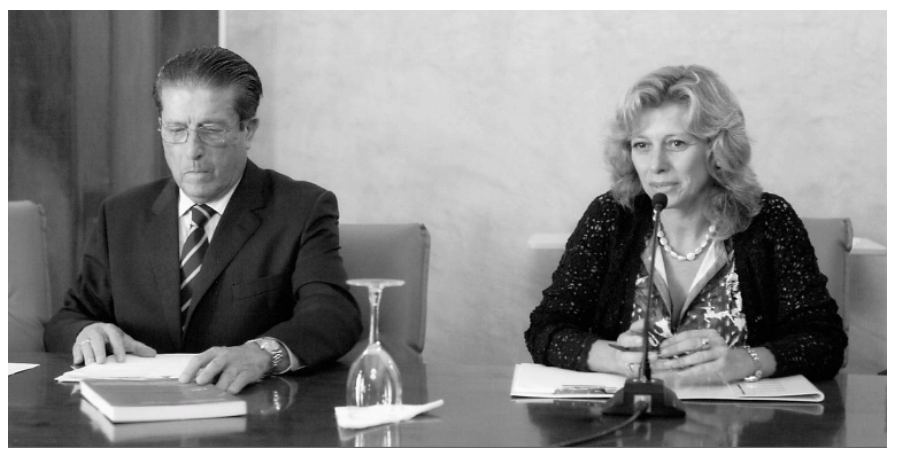

Marycruz con el Profesor Federico Mayor Zaragoza, Director General de la UNESCO.

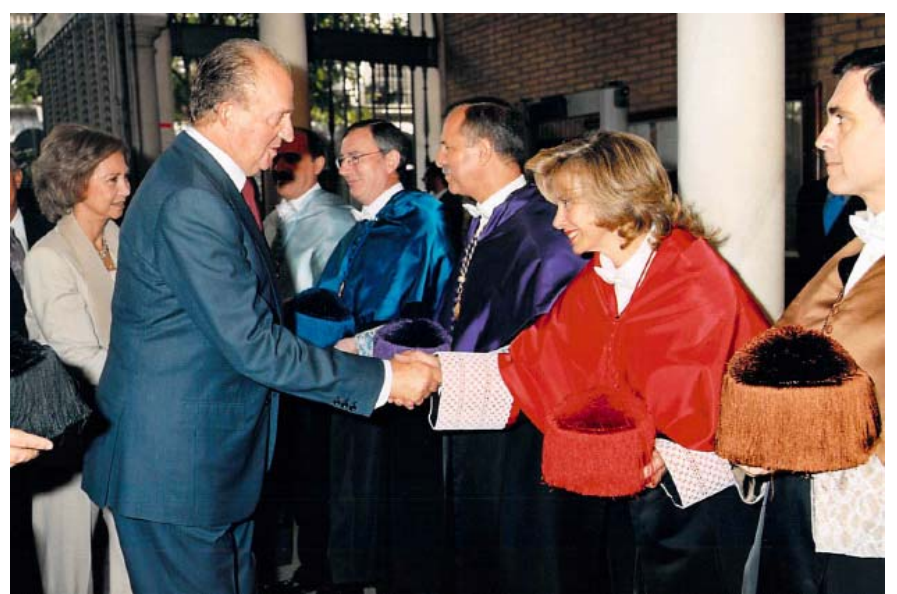

Saludando a los Reyes junto con otros compañeros del equipo Rectoral (el Prof. Joaquín Luque será Rector en 2008-2012).

Marycruz y su marido se responsabilizan del cuidado de sus hijos, distribuyéndose el tiempo. $Y$, además, se necesita ayuda. Una señora realiza las tareas domésticas. Es una más de la familia en la que trabaja desde hace 20 años. Era "la 
tata" de los niños en casa de su suegra. Sus hijos comen en el Colegio; ella y su marido comen fuera de casa. Por eso Marycruz dice que no concilia, refiriéndose a una de las consideraciones más frecuentes sobre la conciliación que es la posibilidad de compaginar bien las tareas del hogar y las profesionales: "Ninguno de los dos hace casi nada en casa". Lo cual no es del todo cierto, porque la señora que cuida la casa tiene su vida y tiene sus fines de semana libres. Pero, sobre todo, porque es preciso dedicar el tiempo necesario a los niños, y eso se hace con organización, y contando con las condiciones de trabajo de los profesores:

La flexibilidad de horario que tenemos en la Universidad es un instrumento para poder conciliar ambas funciones, las profesionales y las familiares. Yo siempre he procurado tener el trabajo terminado para llegar a casa a las 6, y dedicarle tiempo a ayudar en las tareas a mis hijos. Porque les enseño cómo hay que hacer las cosas.

Estar con ellos, ser un apoyo para que hagan los deberes y sobre todo para que aprendan a estudiar, a resolver problemas, etc., en su casa, a su aire, con la confianza de preguntar, oír, y poder mostrar a su madre, profesora de Universidad -con altas responsabilidades en la Universidad de Sevilla durante esos años- los logros del día a día, les da una seguridad importante. Aunque también saben apreciar la mesa de mamá, en colocación, decoración, o en "la pasta que prepara para cenar", como le dijo su hijo un día: "Mamá, hoy he comido los mejores espaguetis de toda mi vida".

En casa, como en la Universidad, bien sea en docencia, en participación en cursos, en gestión, etc., hace de todo. Pero da importancia a lo que son sus prioridades y apenas tiene en cuenta lo que va apareciendo de forma colateral, como si fuera lo más natural.

Vive en Sevilla, cerca de la Universidad. Un loft/live, facilita la convivencia. Un gran espacio diáfano para que los niños jueguen juntos, para que cada uno pueda hacer su tarea o sus actividades de ocio en un espacio compartido: "Una casa para vivir". Y para educar. Pero los niños crecen y quizá deba cambiar el uso del espacio o la estructura de la casa por aquello de la sinomorfia. Ciertas actividades necesitan su espacio, $y$, viceversa, si el espacio tiene una estructura determinada sugiere y hace posibles determinadas actividades.

Sí, sigue siendo un loft, pero el niño, ya en 40 de ESO, ya se mete a estudiar en su cuarto, que eso que a mi me gustaba tanto de todos juntos cada uno haciendo sus cosas... pero es que yo eso lo he vivido en casa. Mi padre haciendo la Tesis Doctoral y todos los demás (5 hijos, ella la mayor) haciendo deberes, en la mesa del comedor. Allí nos sentábamos todos y el más chico se levantaba y merendaba y encendía la tele y nos daba igual... Sí pero algo va cambiando porque ya alguno necesita más su espacio, también a lo mejor la diferencia entre el niño y las niñas... pero yo sigo creyendo en la propiedad comunal... y aprendo todos los días mucho de ellos.

Hay que estar juntos, compartir, colaborar, discutir, observar, enseñar, ... cuidar, mimar..., para poder aprender de los hijos y educarlos. 


\section{Su educación. ¿Quién educa a quién?}

Su padre era ingeniero. Su madre es abogada. Tiene 69 años. Aún sigue en ejercicio, porque le gusta su trabajo. Su especialidad son los temas de familia y a veces temas de derecho financiero. Tiene el despacho profesional en su casa. Una mujer estudiosa y trabajadora, a quien le gusta el Derecho. Empezó el doctorado en Derecho Político, pero dejó de trabajar al nacer sus hijos. Marycruz, la mayor, al terminar la carrera animó a su madre a colegiarse y a continuar con su profesión. Sus hijos ya eran mayores. Se reincorporó al trabajo y ya no para, porque le gusta.

Al pensar en su formación, Marycruz reconoce la influencia directa de personas clave:

Mis padres, los dos, en valores y en estudios; sobre todo en el sentido de la responsabilidad. Y mi maestro, el profesor Carrillo; mi jefe espiritual. Por supuesto, también tienen su influencia mi marido y mis hijos.

\section{Vocación: Descubriendo el Derecho}

Su carrera profesional ha seguido una línea coherente, el Derecho Internacional, alrededor de la cual se han estructurado su formación y todas sus actividades. Es su gran motivación, que descubrió al estudiar la carrera. En el momento de elegir estudios universitarios, pensó en Filosofía en primer lugar, porque sus intereses giraban sobre el mundo de las ideas, y de la organización de la sociedad. Pero la buena nota de selectividad $(9,7)$ fue un factor importante que utilizaron diversas personas de su entorno para que se replanteara su elección:

Mi madre me convenció para que hiciera un primer curso de Derecho. Tuve la suerte de que la primera clase nos la dio el Profesor Antonio Enrique Pérez Luño, Catedrático de Filosofía del Derecho, y descubrí que aquello era lo que me gustaba; en ese momento decidíquedarme.

Marycruz comenta que siempre está en el borde del Derecho, porque se reconoce jurista, pero entiende el Derecho como una Sociología, es decir, le interesa sobre todo "el sentido" de las normas, porque responden a necesidades sociales que se van percibiendo, o son iniciativas que se anticipan a la marcha de la sociedad.

\section{Desarrollo de la carrera profesional en Derecho Internacional}

Ya dentro del Derecho, la inclinación específica por el Derecho Internacional se debe a la influencia de su maestro, con el que empezó a trabajar desde el tercer curso de carrera, ayudando a montar el Centro de Documentación Europea que se estaba creando entonces (1983), y en el que hizo de todo, desde montar estanterías con una llave allen, hacer fotocopias, organizar documentación, etc. Es una persona muy activa, intelectual a la vez que hábil para resolver problemas mecánicos. Por ello, muy versátil. Y no es más que uno de los ejemplos de la realidad que ella expresa en esa actitud de "estar atenta a todos los trenes que pasan y cogerlos". 
Hay un hilo conductor en su trayectoria profesional: la integración europea, como Doctora en Derecho Internacional y Profesora Titular del Departamento de Derecho Administrativo y Derecho Internacional Público y Relaciones Internacionales. Toda su actividad en la Universidad de Sevilla, como profesora, como gestora con distintas responsabilidades, y como investigadora, está orientada por ese objetivo, que evidentemente apunta más allá de la Universidad, a la propia sociedad.

\section{Ser profesora universitaria}

Al terminar la carrera de Derecho, en 1985, tiene clara la orientación de su actividad profesional. Quiere ser profesora de Universidad porque le encanta la docencia, y consigue una beca de investigación para hacer la Tesis en Derecho Internacional. Pero al año siguiente obtiene una beca del Ministerio de Asuntos Exteriores, la más prestigiosa, para hacer un Máster en el Colegio de Europa en Brujas. Este Máster fue planificado con el fin de formar a la élite europea. Eran 300 alumnos de los diferentes países, de ellos 8 españoles, y todos becados; la beca era la única manera de realizar esos estudios.

Ello me proporcionó una formación importante, por los temas, por el uso del francés y del inglés, las lenguas académicas del curso, y por el alto nivel de exigencia. Pero, sobre todo, tuve la oportunidad de conocer a compañeros, que en el futuro desarrollarán funciones a nivel internacional, conviviendo como en un barco, con unas relaciones muy estrechas, dada la situación y el tipo de población de la ciudad de Brujas.

Algunos de esos compañeros en la actualidad son Diplomáticos, o desarrollan funciones en la Comisión Europea, y en otras Instituciones Europeas. Ella misma recibió, al terminar, una propuesta para trabajar en el Parlamento Europeo; una opción interesante si no hubiera tenido tan claro que su puesto está en la Educación Superior.

En 1987 vuelve a su Universidad porque piensa que debe ofrecerle lo que ha aprendido, y materializar las ideas en proyectos ante los cambios políticos y de política universitaria que se están produciendo en Europa. Su formación, como toda su actividad, comienza con la investigación:

1. Primero, investigar: La Universidad debe ser protagonista y líder en el mundo del conocimiento", para poder ser útil e iluminar a una "sociedad del conocimiento"3 , "porque si no haces investigación, ¿qué enseñas?

La Tesis doctoral continúa en la línea que había comenzado con la Tesina y el Máster. Se centra en el estudio de los Procedimientos de decisión en la Unión Europea. No le interesaba tanto lo que decide, que es mucho y que desciende a cuestiones de todo tipo, menores y mayores (como por ejemplo, el tamaño de los botes de mayonesa, o la producción del aceite de oliva,... o la mediación en conflictos

\footnotetext{
2 Estebaranz, A. (2002) Los caminos de la Universidad. En Garrido, I. Lopes, S. Cunha, M.I. Gue, J. (Eds.) Os rumos da Educaçao Superior. Sao Paulo (Brasil) Editora Unisinos.

3 Comunicación de la Comisión al Consejo, al Parlamento Europeo, al Comité Económico y Social Europeo y al Comité de las Regiones (4.10.2006). Una Europa Global: Competir en el Mundo. Una contribución a la Estrategia de crecimiento y empleo de la UE. Bruselas. http://europa.eu/ legislation_summaries/external trade/r11022_es.htm
} 
internacionales) y por qué lo decide, "sino cómo se deciden los equilibrios de poder". Presenta su Tesis en noviembre de 1991, un momento muy especial en la Unión Europea. Tan especial, que en febrero 1992 se estaba aprobando la gran revolución en ella: La aprobación del Tratado de Unión Europea.

Por ello, era un tema que estaba "totalmente hirviendo", "ibas tratando documentos en caliente" en esos momentos. Lo cual era una gozada.

Pertenece al Grupo de Investigación: Derechos Humanos, que creó y dirigió el Profesor Carrillo Salcedo, cuyos Proyectos de investigación se integran bajo el título: "Organizaciones internacionales, estados y derecho en la era de la globalización". Y que actualmente desarrolla varias líneas de investigación: Inmigración y Obligaciones Internacionales en Materia de Derechos Humanos. Globalización de la Justicia (Unión Europea y Protección de Derechos Humanos, Sistemas Europeo e Interamericano de Protección de Derechos Humanos; Protección Internacional de Derechos Humanos en el Sistema de Naciones Unidas. Corte Penal Internacional); Derecho de la Unión Europea; Relaciones Internacionales; Derecho Internacional Público.

Marycruz dirige algunos Proyectos, como The New Civil Procedural Law of the EU (2009-2011), financiado por la Dirección General de Justicia e Interior de la Comisión Europea. Pero también desarrolla como responsable Contratos para la Organización y Coordinación de la acción formativa denominada: "Instituciones europeas". Contratos 68/83 financiados por la Secretaría de Acción Exterior de la Consejería de la Presidencia de la Junta de Andalucía como Instituciones Europeas (2008) y Política Social y de Empleo en la Unión Europea (2009).

El grupo de investigación lo forman 11 miembros, 3 de ellos jubilados, uno de los cuales es J.A. Carrillo Salcedo, el promotor de esta orientación en las líneas de investigación. Cuyos resultados han publicado de forma conjunta en diversas revistas como la Revista de Instituciones Europeas; Crónica Jurídica Hispalense... y libros. En la realidad cuentan con el conocimiento experto.

Cuando Marycruz comenta la satisfacción que le produce poder difundir el conocimiento, pone el ejemplo del último libro, publicado en 2011 por Tecnos, una editorial prestigiosa en Derecho, que precisamente está hecho en colaboración, a petición de la propia editorial:

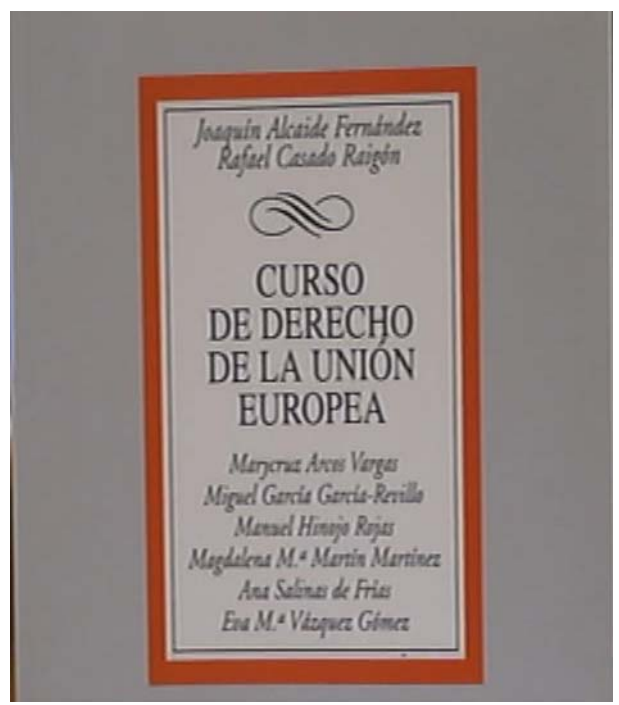

Es un manual colectivo que nos pidió Tecnos: Lo solicitó la editorial y encargó a cada persona, de las tres universidades: Málaga, Córdoba y Sevilla, el capítulo correspondiente, del que estamos muy orgullosos porque hemos logrado sintetizar y clarificar el Derecho de la Unión Europea para no iniciados, en 20 páginas cada tema; y está teniendo un éxito bárbaro, para una asignatura que es obligatoria, además en primero, y en un semestre, en las Titulaciones de Grado. 


\section{La práctica de la buena enseñanza.}

Pero también había que usar el conocimiento para la formación. Y tuvo la oportunidad de poder enseñar su materia en los distintos puestos que ha desempeñado en su Departamento, desde que en 1987 obtuvo un Contrato de Ayudante de Escuela Universitaria; después contrato de Profesora Asociada de Universidad; Contrato de Interina, y en el año 1994 sacó la plaza de Profesora Titular de Universidad.

Por ello, desde que volví de Brujas me concentré en ofrecer cursos sobre la Unión Europea, que era una laguna en la formación de juristas. Estos cursos se desarrollaban los sábados por la mañana, y se ocupaban todas las plazas (más de 100 personas). Porque había necesidad. También me encargué de otros Seminarios sobre la "Integración Europea" para alumnos, a los que asistían alumnos de Derecho, de Económicas, de Ingenieros, de Historia, etc. Eran temas que aparecían de forma tangencial en diversas especialidades y el Seminario les proporcionaba un sentido de unión y de relación entre ellos.

\section{Sus competencias docentes: Involucrar a los alumnos en su ámbito de conocimiento}

Ser profesora universitaria es ejercer una función de liderazgo. De liderazgo intelectual y social. Y este liderazgo se apoya en la claridad de las ideas que se exponen, en la motivación y convencimiento del sentido de lo que se enseña; y en la comunicación personal que es trasvase de conocimiento y estímulo a la curiosidad, contagio de la necesidad de conocer y comprender, y comprensión de lo que el otro, los otros, comprenden y necesitan comprender.

\section{a) Enseñar es su pasión: Motivación personal y capacidad de entusiasmar}

Los primeros pinitos en la docencia se desarrollaron en esta línea. Impartía Derecho Administrativo, pero daba prácticas con una orientación en temas europeos. Ya Doctora, el tema de su Tesis forma parte de todos los Másters. Es un problema transversal que interesa a distintas profesiones. Además, su docencia se centra en el Derecho Internacional, que es su pasión y su dominio de conocimiento:

$Y$ descubro que me gusta mucho lo que estoy haciendo. Estoy convencida del sistema, me gusta; podría sobrevivir con cualquier cosa, pero tengo que estar convencida de lo que estoy haciendo y cuando trabajo en temas europeos me sale bien.

Después de 25 años de docencia, puede reconocerse esta competencia aunque se siente incómoda con la pregunta y le cuesta responder ${ }^{4}$

\footnotetext{
${ }^{4}$ Es tan expresiva, que se puede entender mejor su explicación de lo que es transmitir lo que sabe y aquello en lo que cree, lo que piensa, lo que se hace cuando se resuelve un caso jurídicamente, etc., si se ven los gestos y se oye su tono, que nunca pierde el agrado. Hay explicaciones largas cuando le disgusta la mala docencia. La expresión es diferente cuando habla de temas que disfruta: el trabajo, la responsabilidad, las relaciones, los alumnos, los programas de apertura al exterior, las relaciones con compañeros... Por ello, vinculamos el texto con los fragmentos de vídeo correspondientes.
} 
Pues mira, yo creo (y ahí está las evaluaciones) que transmito. Yo creo que, para mí lo más importante, que ilusiono ¿sabes?... que al cabo de los años, que vienen muchos antiguos alumnos: $V d$. me dio clase, y me contó algo que me abrió una ventana y por ahí voy a trabajar. Es verdad que eso son una aguja en un pajar... hay muchos que les da igual ocho que ochenta lo que yo les conté, que no les importa nada, y que piensan que vaya tostón que nos está dando... con lo europeo, si me quiero dedicar a otro tema del Derecho ...

Por eso yo empecé con Derecho Internacional Público, mantuve docencia en Derecho Internacional Público y Derecho de la Unión Europea prácticamente hasta que aterrizó el Plan Nuevo, y ya en el Plan Nuevo había muchísimos grupos de Unión Europea, por ello yo concentré la docencia en Derecho de la Unión Europea "Si el año pasado superé los 24 créditos, porque a mí no me importan las clases, es que me gusta, vamos me gusta hasta el punto que voy aparcando la investigación" Me lo paso tan bien, que cada vez que hay una clase que alguien no puede dar, con créditos o sin créditos voy y la doy yo. Me gusta mucho dar clases, me dan muchas satisfacciones los alumnos...

\section{b) Tener algo valioso que enseñar}

El desafío de Marycruz como profesora es lograr la comprensión en profundidad del sentido de las leyes por los estudiantes o los profesionales que participan en los cursos de Derecho Internacional. Le satisface poder enseñar su filosofía, explicar qué hay detrás de las normas, porque le gusta transmitir lo que sabe y lo que piensa, bien sea a profesionales de reconocido prestigio o a alumnos de segundo.

Los temas que explico, a lo mejor es la primera vez que oyen hablar de ellos, y veo que me siguen, y me emociona.

En la visión de Marycruz lo primero que importa es enseñar algo importante, valioso. Ser profesor es tener algo que enseñar, que forme a los jóvenes haciéndoles ver las conexiones del mundo jurídico con el mundo económico, la dimensión internacional de las empresas, y las distintas funciones que como juristas van a tener que ejercer, o van a poder ejercer.

\section{c) Estructurar la formación: "No desembarcar directamente en lo particular"}

Marycruz enseña Derecho de la Unión Europea en primero de la nuevas Titulaciones y en Máster. Poner el esqueleto y rellenarlo. Enseñanza "multilevel".

Al principio empecé mi formación con Derecho Internacional Público -lo general- y Derecho de la Unión Europea -lo particular-. No te enteras si no coges la filosofía de la Unión Europea... Agradezco a mi maestro que nos ordenase la cabeza. Enseñaba y estudiaba Derecho Internacional. Y daba cursos también...

Esa doble dimensión, con los de primero y con los del Máster, a mí me está gustando. Dado Derecho Internacional en primero, en Máster se supone que ya conocen el efecto directo de las normas de la Unión Europea y ahora es cuando se puede profundizar en cómo una sentencia en la que se vea como una directiva puede producir efectos directos. Es apasionante, ya puedes profundizar... 


\section{d) Abrir caminos en el conocimiento}

Como Coordinadora, y especialista de Derecho de la Unión Europea, su papel es crear y poner en marcha las materias que se van a enseñar:

Luego cuando ya hay muchos grupos de Derecho de la Unión Europea como asignatura específica, la mayoría de mis compañeros prefiere Derecho Internacional. Y me vuelco en esta materia, sobre todo en lo que es abrir nuevas líneas, las optativas,... crearlas, y puestas en marcha, después se ocupa otro.

\section{e) Lograr la comprensión de la materia y el uso del conocimiento}

Enseñar para que comprendan lo importante, lo relevante en el mundo de hoy, globalizado, relacionado, es un reto, pero es el valor de la formación de los jóvenes, que tienen que aprender a comprenderlo y pensar en el valor relativo de determinados hechos en comparación con otros que ocurren simultáneamente y que implican a las instituciones y a los profesionales del Derecho. Y esta característica de la buena enseñanza señala Marycruz que es algo que ha ido aprendiendo a lo largo de sus años de práctica. Estamos hablando el 8 de febrero de 2012, por eso los ejemplos son del día, pero el criterio de actualidad es fundamental para que los estudiantes universitarios entiendan el sentido de lo que estudian, por cierto, el mayor factor de motivación:

No podemos pensar que nos importe el reto de la deuda griega y que nos dé igual el veto de la resolución de la ONU a Siria, me parece gravísimo... Es mucho peor el posible cierre del Estrecho de Ormuz; las consecuencias del cierre son mucho peores que el hecho de que Grecia se declare en suspensión de pagos. Por ello no podemos estar enseñando o empezar sólo por lo concreto...

Yo estoy acostumbrada a trabajar en una materia, en la que los Power Point de un año no me sirven para el otro, si lo que pretendo es ir al dato, porque las leyes me las cambian cada poco tiempo, no te digo nada en el Derecho material, que cambia dos veces por día, pero lo que es el Derecho estructural cambia con una cierta frecuencia... No es eso lo importante, como yo me preocupe del dato, esto va a durar..., cuando terminen la carrera esos datos son distintos, no ya solo en Derecho de la Unión Europea, en Derecho en general. Desde el Derecho que yo estudié, hasta el que hay ahora mismo en vigor, ha cambiado todo, es que no tiene nada que ver el dato del Derecho Mercantil, del Derecho Civil,... es que yo estudié Derecho Civil (años 80 del siglo XX) cuando las mujeres necesitaban el permiso marital para sacarse el pasaporte..., si yo me hubiera quedado en ese dato de qué me sirve?

¿Qué es lo que yo necesito transmitirles a los alumnos? Estructuras jurídicas para poder pensar en Derecho. Entonces, para mí es muy importante, que ellos con la Legislación en la mano sepan resolver un caso. Ahora, primero tengo que sembrar un poquito: primero que sepan qué es la legislación, que sepan lo que les estás pidiendo, pero yo con los años cada vez les digo más que mi asignatura se aprueba con comprensión lectora y con razonamiento lógico, y creo que esos eran los objetivos de 3 de Primaria... Bueno, ahora me dicen que ya no se llama comprensión lectora, que ahora se llama de otra manera, pero... si leen y se enteran de lo que están leyendo, y son capaces de razonar lógicamente..., el Derecho es pura lógica; no me puedo preocupar por los datos. Que aprendan a pensar con estructuras jurídicas, hay cosas, que nos pueden rebelar personalmente y podemos plantearnos, bueno, ¿esto cómo es posible? Es posible porque es lo que está escrito. Podemos cambiar el Derecho, pero lo que está escrito es lo que 
está escrito, y tenemos que aprender a aceptar las reglas, las reglas que hay. Y si queremos modificar las reglas, las modificamos, pero no incumplirlas.

\section{f) La enseñanza y el aprendizaje de valores en Derecho}

Cuando le preguntamos qué aprenden sus alumnos, y cómo evalúa las competencias que se propone, "comprender y razonar", cómo ha comentado antes, amplía su visión del sentido formativo de las materias que enseña; van apareciendo los valores tan necesarios en el mundo de hoy, y específicamente en el mundo de la justicia, donde lo permanente no son las normas, que cambian, sino los valores y los principios de actuación:

Lo intento, también hay habrá alguno que me da el timo, que al final se copia... Yo siempre les digo que procuren no hacer trampas. Por una razón muy sencilla: si son capaces de hacer una trampa para algo que tiene tan poco valor como aprobar o no aprobar esta asignatura, cuando tengan que tratar con 2.000 millones de Euros de qué no serán capaces? Por lo tanto, por su propia salud mental, no hagan trampas. Y yo creo que se copian poco. Y además el que se copia, es que lo hace tan mal el pobre... Es que lo pongo en el Google entre comillas y sale íntegro. No se molestan... Pero de eso cada vez hay menos... Es la selección natural... Yo puedo valorar... la norma nos dice que no podemos valorar negativamente al que no haya ido a clase, pero yo voy a valorar positivamente al que ha venido a clase y la aprovecha... Por lo tanto no voy a hacer control de asistencia..., ocasionalmente... tres o cuatro veces a lo largo del semestre llevo una lista y firman. Y el que quiera firmar en el sitio de su compañero... pues peor para él, pero lo importante es que el que ha seguido habitualmente el curso... ése ha aprendido a razonar, ése ha aprendido que esto de la Unión Europea no es algo que esté en Bruselas y que no nos afecta, no, no, que esto es algo que tiene que ver con nosotros, y que tiene que ver... Verás yo les insisto mucho en los valores, en los principios... porque creo que eso es lo permanente. Lo demás no, pero los valores y los principios sí: la apertura al otro, el concepto de las solidaridades de hecho, el poder trabajar en la diversidad... que bueno... a lo mejor eso es educación para la ciudadanía que no nos hemos enterado todavía... y con lo cual estamos dando educación para la ciudadanía en 1o de carrera, y en el Máster también...

\section{g) Usar la metodología apropiada}

La enseñanza incluye variedad de formas de aprender. Pero la buena enseñanza es ante todo comunicación. Es una competencia que va a ir apareciendo a lo largo de su historia de vida profesional en los distintos campos de su actividad. Comunicación que en clase empieza siendo unidireccional pero que progresivamente va siendo más participativa, y tiene lugar tanto de forma presencial como on-line. La clase se complementa con lecturas personales y trabajo práctico. De todas formas, la metodología viene condicionada por los objetivos del programa y por los recursos disponibles.

\section{* Explicar, y responder a preguntas}

Bueno, yo hago clases teóricas, sigo un modelo muy tradicional, hablo, y hablo, y hablo. Ellos preguntan, pero no hay momentos preguntas, sino que intervienen en la medida en que van surgiendo. Al principio están todos callados, escuchando, muertos de miedo. Yo 
creo que no entienden más de un $20 \%$ de lo que voy contándoles, pero algo va quedando, al menos los términos, y bueno vamos desarrollando los temas del programa.

\section{* Prácticas: proponer y tutorizar}

Hay diferentes tipos de prácticas, según se trate de las prácticas de cada materia o de las prácticas externas, que se hacen en empresas o bufetes, $u$ otras instituciones. Pero son determinantes el nivel de los alumnos, o las características del curso de que se trate (Grado o Máster).

En primero son muy difíciles las prácticas, pero, reflexionando un poco sobre el tema, es lo que más les queda a los alumnos...

Los trabajos prácticos (antes habló de la resolución de casos con el Derecho en la mano), yo lo que hago es que se los envío. Las NT es que nos han puesto en casa, eso... no tiene nada que ver con lo que pasaba antes. Tiene un peligro tremendo, porque como ellos viven enganchados al chat, se creen que tú también, entonces te mandan un trabajo... y eso sí que lo he notado en cuanto a los alumnos de la doble titulación (Grado en Derecho y Gestión y Administración Pública) que se les nota la nota de selectividad, se les nota. El principio de mérito y capacidad..., oye si está en la Constitución... Bueno, pues te mandan un trabajo, y no le has contestado y no le has mandado el mensaje de recibido, conforme. Y te vuelven a mandar otro correo diciendo: ¿es que no le ha gustado mi trabajo? Mire Vd., no estoy on-line, esto no es un foro... yo también hago otras cosas..., yo me ocupo de Uds., pero no sólo.

Ahora las ventajas, son muchas. El alumno que quiere me lo manda a las 2 de la mañana, si le apetece, y yo me lo leo a las 6 de la mañana y le contesto, porque yo estaba durmiendo a las 2, porque si no no puedo leer y comprenderlo porque el razonamiento lógico y la comprensión lectora también tiene que funcionar en mi cabeza...

\section{¿Quiénes son los buenos alumnos?}

Para Marycruz, los buenos alumnos, como los buenos profesores son aquellos que quieren aprender. Los que tienen motivación e ilusión. $Y$ eso les conduce al trabajo: lectura, participación, realización de tareas propuestas.

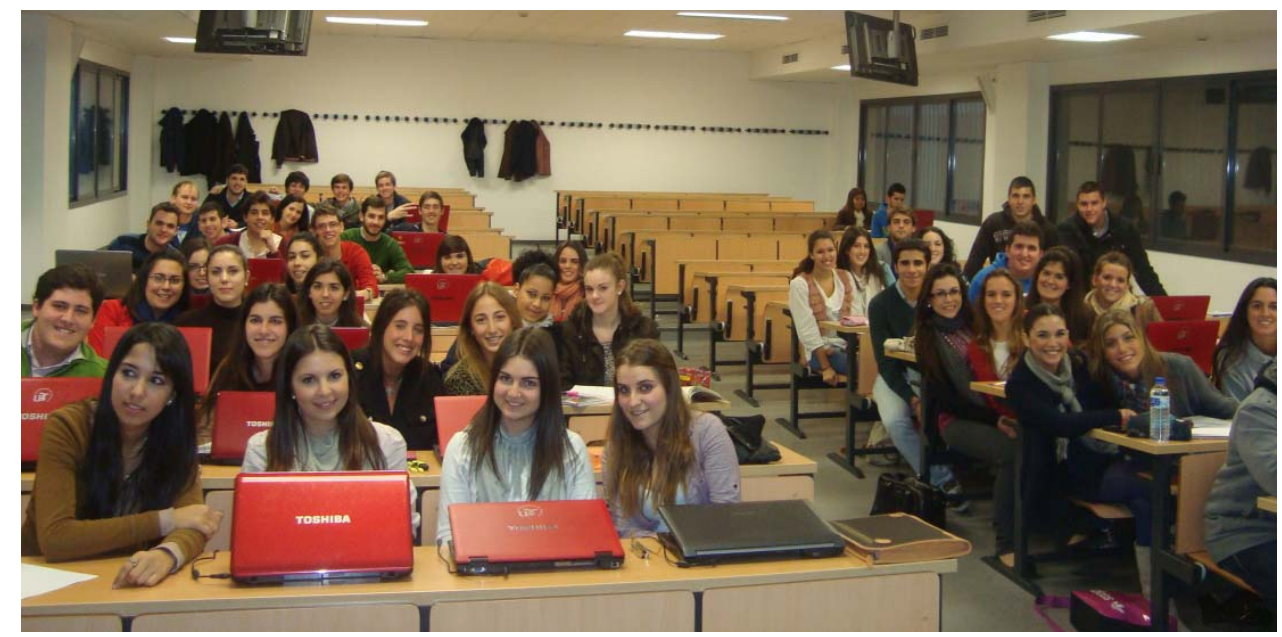

Estudiantes de Derecho de la Unión Europea. Clase de Marycruz (1-III-2012). 
Pero tienen mucho que aprender, desde aprender a situarse en la Universidad y en la carrera, a aprender a pensar y a realizar las tareas de la profesión en un contexto.

Y sí hay mucha diferencia entre alumnos de Derecho y de la doble. En Derecho este año han entrado con un 7'8 (que sobre 14 es un 6, tampoco es gran cosa). Los de la doble han entrado con 12 y pico. No es que sepan más cosas (algunos) es que tienen más ganas de aprender, tienen más disposición, y entonces cualquier cosa que les recomiendes, tú les dices: léanse esto. Por supuesto, yo les hablo de Vd., cercanísima... Tengo un Tuenti, estoy participando en Tuenti porque me invitaron los alumnos, y yo estoy muy orgullosa. Eso me hizo una ilusión..., bueno, un premio... Cercanísima, pero mientras sean alumnos aquí nos hablamos de Vd., y ellos aprenden a hablar de Vd..... Cuando llegan aquí mis chicos de 18 años no han hablado de Vd en su vida. Y creo que también les debo formar en formas $y$ en principios y valores. Efectivamente esto no es el programa de Carmen Lomana, pero yo llego a clase y le digo a uno ¿Podría quitarse la gorra? Y me dice: ¿es que no le gusta?, pues es de "Quiksilver"... Pues mire Vd., no es que no me guste. Yo entiendo que es una formalidad, es una convención, pero cuando estamos a cubierto, salvo que Vd. tenga algo en la cabeza, debe quitarse la gorra. ¿Es mi labor tener que explicarles a los alumnos que no se usa gorra en clase? Pues yo entiendo que sí aunque pierda 5' de una clase; si nadie se lo ha contado antes, bueno, que cuando salgan de la Facultad sepan cómo presentarse. Les digo: Iría Vd. así a una entrevista de trabajo? Y alguno me ha contestado: pues depende de qué tipo de trabajo sea... Pues también es verdad, si $\mathrm{Vd}$. desea que le contraten como portero de discoteca quizá podría ir así...

$Y$ luego que yo pienso que tampoco hace falta ir de marcas, pero sí vestirse con respeto, con discreción... Pero ellos tienen que aprender que también eso es importante. Y a lo mejor eso debería habérselo enseñado su maestro de primaria, o en su casa, también..., y si no se lo han dicho antes, pues habrá que echar un ratito..., después me como el intermedio de la clase...

Siempre es ella misma. Una madre sencilla, que enseña a sus alumnos con agrado los detalles, sin reñir. Y se lo aceptan. Después distingue entre los alumnos del primer semestre y los del segundo. Vienen más abiertos e ilusionados los del primer semestre, porque en febrero llegan cansados de los exámenes, y puede ser que ello influya sobre la motivación de los alumnos.

\section{El impacto de la formación}

La buena enseñanza tiene un impacto importante que se descubre en la vida personal y en la vida profesional de los que han sido formados en determinadas competencias, pero también en las relaciones que mantienen; por eso preguntamos a Marycruz en nuestra última entrevista: ¿Qué relación ves entre las materias de Derecho Administrativo, Internacional y Europeo, y los despachos de abogados de Asesoramiento Internacional, que se han ido abriendo en Sevilla? También recogimos datos sobre determinadas actividades y la relación que mantienen con la Universidad de Sevilla, cuando descubrimos la relación temporal que guardan con el hecho de haber cursado esas materias. Asimismo, nos sugirió la pregunta el conocimiento de algunos abogados dedicados desde sus inicios profesionales al Derecho Internacional.

Desde 1992, con ocasión de la celebración de la Expo-92, que sin duda fue una oportunidad, comenzaron a abrirse despachos de abogados especializados en Derecho 
Internacional (hemos podido localizar como 12 despachos que se abren en los años 90) con el fin de proporcionar asesoramiento integral a empresas, un eje vital para el buen funcionamiento de la empresa y para la optimización de sus recursos. Después, como cualquier empresa, estos bufetes buscan su expansión en cuanto a líneas de trabajo y en cuanto a localización: y van creando sedes en otras ciudades, Badajoz, Córdoba, Lisboa..., a veces en calidad de despachos asociados. Suelen ser despachos interdisciplinares que se anticipan con el asesoramiento o resuelven problemas de negocios, contratación y operaciones Internacionales: Arbitraje Internacional; Derecho Comunitario; Relaciones con Iberoamérica; Derecho Penal Internacional; Derecho Fiscal Internacional; Planificación Internacional de Patrimonios; Derecho de Comercio Internacional; Derecho de Familia Internacional, etc. La respuesta de Marycruz es contundente, siempre con la misma naturalidad:

Normalmente quienes han estudiado en Sevilla y se están dedicando a estos temas suelen tener contacto conmigo. Mira, hemos quedado con una señora, funcionaria de la Comisión que trabaja en ayudas de Estado, que es un tema muy importante, y viene a Sevilla y me puso un correo: mira, me gustaría conocerte, porque hay antiguos alumnos tuyos que están trabajando aquí y me han dicho que no deje de conocerte...

Marycruz disfruta con el éxito de sus alumnos. Mirando a distancia se puede reconocer el impacto de la formación por sus logros profesionales y sus acciones comprometidas con la sociedad. Es la satisfacción que sienten los buenos profesores cuando encuentran indicadores del desarrollo profesional y social de sus estudiantes, y en su caso lo va reconociendo al identificar a cada persona de la foto de los Licenciados en Derecho, que fueron alumnos suyos también y que considera "ilustres" en la actualidad: Profesora Titular de Derecho Administrativo y Derecho Internacional Público y Relaciones Internacionales; Parlamentaria andaluza; Diplomática; Asesor de Presidencia del Gobierno y Profesor Titular de Derecho Constitucional; Profesor Titular de Derecho Internacional; Abogado...

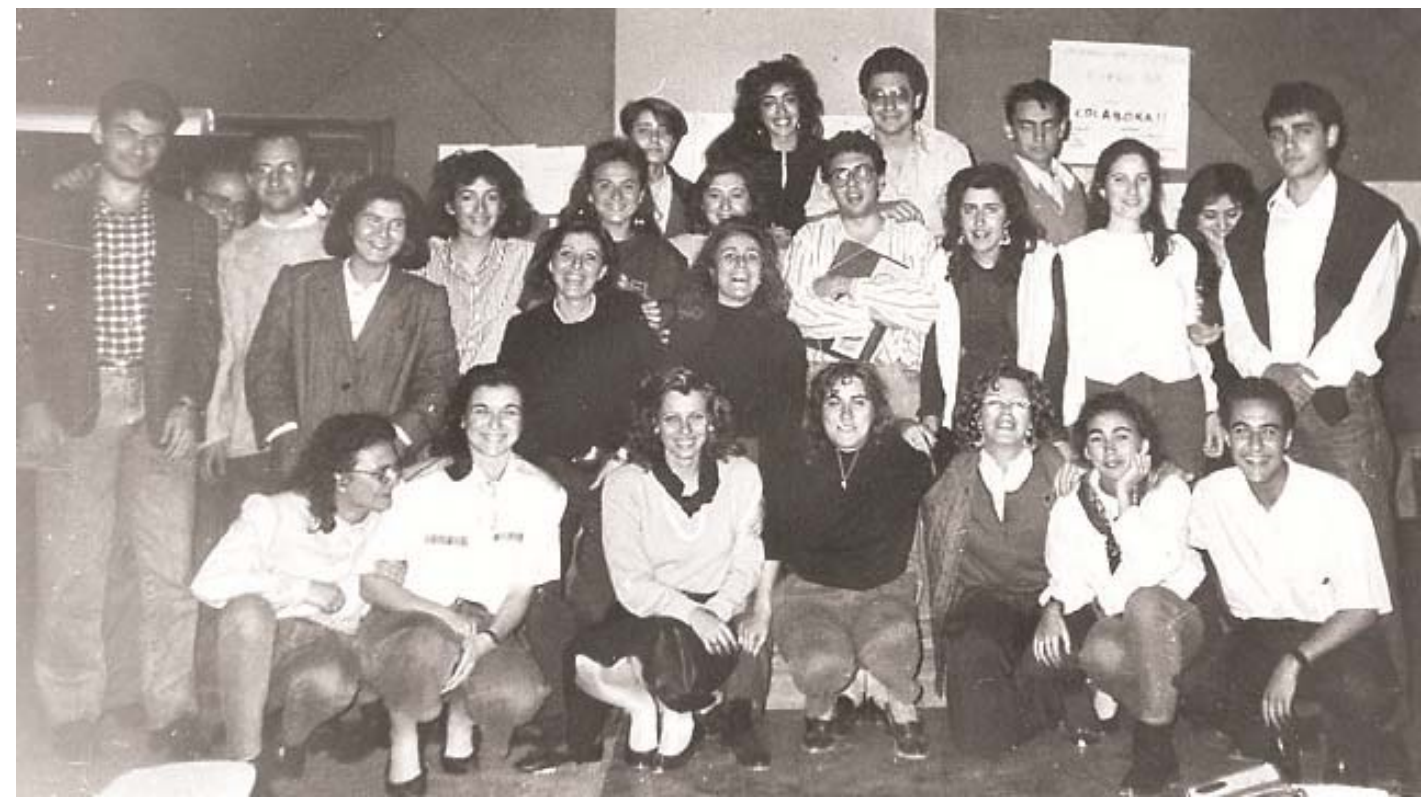

Alumnos de Marycruz del año 1988, Licenciados en Derecho. 


\section{¿Qué es la mala docencia universitaria?}

Cuando le preguntamos qué le parece que es mala docencia universitaria, cambia el tono y la expresión de su cara:

Los que aburren a los alumnos, los que desmotivan, los que hacen que piensen que aquello... que lo tienen que estudiar porque es obligatorio... porque no hay más remedio... Pero eso... en la universitaria y en todo, porque el pobre que ha tenido mala suerte porque ha cogido un mal profesor de matemáticas en primaria ese odia las matemáticas para toda su vida... o el inglés...Pero...en la Universidad tenemos la ventaja de que también estamos investigando, pero que no somos investigadores en un fanal. Si tú estás investigando tú te crees lo que enseñas porque claro cada vez vas leyendo más cosas y dices: oye que es que hay mucha gente que piensa sobre estos temas, y participa en estos temas... $Y$ entonces, como tú te lo crees, tú lo transmites, y como tú lo transmites, tú enganchas a los alumnos, y esto es una cadena...; $y$, claro, en el momento que tú rompes esta cadena, pues porque tú... no estudias... Un profesor que no estudia... "si la sal se vuelve sosa ¿quién nos salará?" Si tú no tienes preocupación por tu materia, y tú lo transmites, los alumnos se desmotivan, el fracaso académico, pues es una cosa detrás de otra.

...Si tú no tienes nada que decir, da igual cómo lo cuentes. Puedes adornarlo mucho, hacer unos Power Point estupendos...

\section{La Universidad tiene medios para promover la calidad}

En la Universidad de Sevilla, se han arbitrado medidas para promover la calidad. Tres son las más importantes, según señala el propio Rectorado: Inspección docente, formación del profesorado, y proyectos de innovación. Indagamos en la última entrevista sobre el valor que tienen para Marycruz estas medidas, dado que ella ha participado, como Vicerrectora en el gobierno de la Universidad.

\section{a) ¿Cuál es tu opinión sobre la inspección?}

El inspector es necesario en tanto que somos servidores públicos y tenemos que rendir cuentas de lo que estamos haciendo con el dinero público...; no un inspector que vea si tú vas a clase o no vas a clase, sino que también compruebe rendimientos..., tenemos que rendir cuentas de que aquí estamos gestionando un bien público y además no sólo dinero público, sino un bien público como es la formación de los futuros profesionales, y entonces hay que rendir cuentas de lo que estás haciendo... Si tú estás cumpliendo con tu trabajo... pues a ti te da igual que miren si lo estás haciendo o no, porque como estás tranquila no hay problema. ¿Es necesario que haya una persona que vaya a comprobar si cuando tú has firmado estás en clase? ... Hombre es que si no salen los alumnos al pasillo y te montan un pollo... ¿Pero qué es lo que pasa? Que... (mi impresión personal), creo que ha habido mucho abuso sistemáticamente aceptado, y a eso le añades que nuestros alumnos cada día son más conformistas y están más pasivos. No dicen nada de la clase que no se da. ¿Que no viene el Profesor? Pues da igual, y nadie protesta...

Si los que nos podían dar la voz de alarma, que son los alumnos, no nos dan la voz de alarma, pues habrá que poner un control de entrada y salida.

En la Universidad, si tú no quieres trabajar, no trabajas, y se nota muy poco, y eso es muy triste; ¿tú quieres venir todos los días a las 8 de la mañana e irte a las 3 de la tarde o venirte a las 3 de la tarde e irte a las 10 de la noche y no dar ni chapa durante todo el tiempo...? Puedes hacerlo y encima con apariencia de que estás haciendo tu trabajo. ¿Tú 
quieres ir a clase y leer unos papeles amarillos de hace no sé cuánto tiempo y cuándo te pregunta alguien le contestas: léalo Vd. en el libro... Pues para eso no me ocupe mi hora de clase. Entonces, el inspector, si al menos eso lo evita, el descaro, que ha habido mucho...

¿Tiene que ver con la calidad o con el cumplimiento?

Claro, es lo que puede controlar el inspector. Y que no aparezcan papeles con firma puesta y la clase vacía... No me tome el pelo... es que le estoy pagando por esta hora... Si cobráramos por cada hora de clase que diéramos... verías si teníamos cuidado con el cumplimiento.

Hay quien dice que "trabajar en la Universidad es estupendo si no fuera por la puñeterita hora de clase..."

Claro, es como que nos estorba la hora de clase...Que no, mire, que esto es la performance de nuestra profesión. Mire, es que yo todo lo que llevo haciendo durante esta semana, tengo esta "puñeterita" hora en la que ponerlo en práctica. Ahora ¿qué pasa? Pues que si yo me estoy dedicando a hacer informes de esos que se cobran por el $68 / 83$, o aquellos que no se cobran por el 68/83..., o estoy preocupado por cosas mucho más banales, veras, que hay gente que está preocupada porque se está leyendo una buena novela y no quiere dejar de leérsela, pues entonces sí. Ahora la hora de clase, a cualquier hora que te la pongan es mala, porque arrancar la mañana..., y si te la ponen a media mañana... me han partido por la mitad, y si te la ponen a la hora de comer, los niños tienen hambre y tú también, y por la tarde... es que los coges cansados...

\section{b) La formación de principiantes y continua}

En este punto volvemos a lo personal. En la Universidad de Sevilla hay planes de formación que se ofertan a todos los Departamentos desde hace 20 años, el programa de formación para profesores principiantes que inició el Profesor Carlos Marcelo y que se desarrolla a través del ICE, que continuaron las profesoras Sánchez y Mayor. Pero algunos Departamentos tenían su propio Plan de formación, principalmente en Medicina Ingeniería y Derecho. ¿Cómo fue su formación como profesora? Indagamos en la importancia que han tenido en su formación docente los profesores expertos, los estudiantes y los profesores compañeros de Departamento:

\section{* Aprender de los profesores expertos y con ellos}

Al preguntarle por su formación inicial como Profesora, aparece otra vez su maestro, si bien ha tenido una influencia permanente, que continúa presente: 


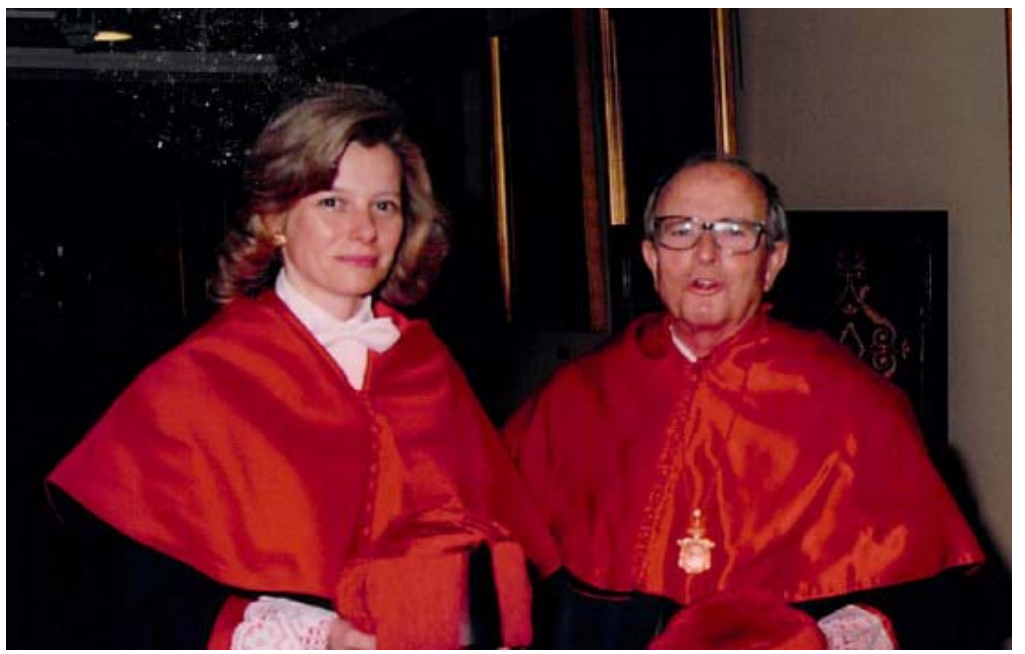

Con su maestro, Profesor Carrillo Salcedo.

Asistíamos a las clases de los mayores, que me encantaba. Íbamos, nos sentábamos en primera fila, y escuchábamos al maestro. Pero el maestro decía: por favor, ve también a clase de (otro Profesor)... que no sea siempre mi clase... Acompañando al maestro estuve por lo menos tres años. Y después yo era ya Vicerrectora, fíjate si había llovido, y dio un año una asignatura optativa de Organizaciones Internacionales que era a primera hora, ... como yo estuviera en Sevilla ese día, yo iba a escucharlo... Y aprendes qué es lo que se da, cómo se da... y cómo se contestan las preguntas... aprendes un montón...

Una vez a la semana nos reuníamos. No para hablar sobre la clase sino para hablar de organización de cursos..., pero claro, también para hablar de noticias importantes, de... ha salido tal curso..., vamos a leérnoslo y lo comentamos... Eso a mí me llenaba una barbaridad... y ahora, ya jubilado, no está aquí todos los días, viene mucho, y nos sigue mandando correos: no dejéis de leeros... porque también está con las N.T.

Pero ahora ya todos tenemos mucho que hacer. Antes, los que entonces éramos pequeños, y entonces yo tenía mi propio curso, no nos importaba acompañar y aprender de los mayores.

Ahora hay medios e instrumentos, pero todo esto hace que los profesores nuevos tengan tantas cosas que hacer que no pueden mirar a su alrededor. Entre que todos tenemos muchas clases, tenemos que hacer cursos. Yo la primera, hoy empiezo un curso de inglés, que mis niños se reían: "mamá tú vas a aprender inglés?", digo: siempre.

Hay cursos que sí, que son necesarios. ¿Cursos sobre técnicas? Es que cambian tanto de una materia a otra... Yo ahora trabajo mucho con compañeros de empresariales, de la rama de Economía porque la Agencia de la Competencia ha creado una cátedra nueva sobre política de competencia, con una pata en Economía y otra en Derecho, de la que me ocupo yo, aunque tenga más de Derecho privado que de Derecho Público, no tiene nada que ver cómo se dan las clases en Economía y cómo se dan en Derecho. Lo que tiene que ver, el contenido de lo que tienen que ver en cada materia es distinto y la forma también. Entonces ¿es posible hacer metodología común? Haría falta una aplicación a la rama, al perfil, y eso se puede conseguir en cursos, o yendo a clase de los mayores. Para ver lo que se debe hacer y lo que no se debe hacer. No te digo que todos los mayores lo hagamos bien.

Pero ella reconoce que ha aprendido mucho de su maestro, de "mi jefe espiritual". 


\section{* Aprender de los estudiantes y con ellos}

Aprender de los mayores y aprender de los pequeños. A mí me da mucha satisfacción cuando vienen antiguos alumnos,... hace una semana tuve invitada en el Máster a una antigua alumna que es profesora en Córdoba para hacer la presentación de un tema sobre el que ella ha hecho una investigación muy buena sobre inmigración y aprendí una barbaridad... no solamente de aquellos que me han enseñado, sino también de aquello que era el desarrollo (la elaboración del cesto completo) de "los mimbres que les has dado", y aprendes mucho, aprendes mucho...

Le preguntamos entonces, ¿sobre docencia has aprendido algo de tus alumnos, has introducido o cambiado algo en métodos en el uso del tiempo, en recursos, teniendo en cuenta a tus alumnos?

Sí. Por supuesto, en recursos. Es que ya no puedes dar clase sin un Power Point. Ya se han acostumbrado a él, que tú un día no llevas Power Point y no te siguen. Yo les digo, pero si esto es como lo del ciego que va cantando con las fotitos... Yo lo que les pongo ahí es lo mismo que mi maestro (Carrillo Salcedo) nos hacía, que no tiene nada que ver con este sistema, pero en el fondo sí: llegaba a clase con un guión en folios fotocopiados y lo repartía, y todo el mundo tenía el guión por delante. Pues eso es lo mismo que yo les proyecto, pero claro, como les vas proyectando cada punto, les pones efectos,... Siempre pienso que tengo que hacer un curso de Power Point para no hacerlo igual...

El trabajar de forma que les cuelgas los documentos en la plataforma y ellos pueden leerlos con facilidad. Las Nuevas Tecnologías nos han revolucionado tanto en el sentido de la pura docencia, como en el sentido del acceso a documentos... Es que yo recuerdo la época, que no hace tanto tiempo, en la que tú tenías que tener un amigo que fuera funcionario en la Comisión Europea y que te mandara una fotocopia con un sello que ponía: "el documento embargado hasta tal hora..." y ahora... es que cualquier cosa que quieras la tienes pinchando, en tu casa...; bueno... eso es una revolución

Pero después también en cuanto a qué es lo que tienes que transmitir. La gente dice es que no me da tiempo a acabar el programa, yo sí, yo acabo siempre el programa. Es verdad que a cada tema le vas echando como a los bizcochos, que vas echando lo que te va pidiendo. Yo llevo un tema preparado y a lo mejor me tengo que quedar en el esqueleto... pues me quedo en el esqueleto, pero puedo rellenarlo un poco más... a veces llego hasta a ver el muñeco y a ponerle complementos, pero termino todos los programas.

¿Qué me han enseñado los alumnos? Que no les atiborre de datos, que no les atiborre de información. Yo les digo dónde está la información y ya le queda a cada uno ir a buscarla. Y te das cuenta... de lo que les queda. Una alumna vino hace unos días, y le había dado Derecho Internacional por lo menos hace 6 años o más... Ya ha terminado la carrera. Y entonces, sería el año 1997, estaba yo obsesionada por mi titularidad, era el tema que yo llevaba como lección: El arreglo de controversia. Los diversos métodos de controversia que hay en el Derecho Internacional. Les hablé de la mediación en unos términos que ella ahora lo estaba utilizando en asuntos varios, porque no se dedica al Derecho Internacional. Y pedía si le podía repetir esa clase (hija... la Magdalena de Proust...) cómo la voy a repetir..., claro, entonces no había presentaciones que colgásemos ni nada... Bueno, pues te vuelvo a contar qué es lo que yo pienso.... Para qué sirve el arreglo de controversia... si lo esencial es el mantenimiento de la norma o lo esencial es que llegue al arreglo entre las partes... qué diferencia hay si trabajamos con soberanos o trabajamos con particulares... Eso es lo importante. No les atiborremos de datos, ahí están, y cuando quieras vuelves al dato... Ve a lo esencial de cada tema. Hay 
temas más esenciales, y temas menos esenciales, que están en programa porque tienen que haber escuchado que existen, pero ya está.

\section{* Aprender con los compañeros de Departamento.}

Su Departamento es grande. En todos los sentidos. Son 54 profesores: 6 catedráticos (una de ellos mujer); 16 Titulares (8 hombres y 8 mujeres); más 32 entre Profesores de Escuela Universitaria, Colaboradores LOU, Ayudantes, Asociados y Sustitutos Interinos. Una composición muy plural que tiene sus ventajas y sus inconvenientes. Ello facilita la relación con la sociedad, y la necesidad de coordinación y de aprendizaje.

¿Qué situaciones propician el aprendizaje? ${ }^{5}$. Es una persona de equipo, de comunicación, y el aprendizaje se produce en las situaciones más diversas, de forma natural. Por ejemplo a la hora de hacer los programas, la comunicación sobre contenidos, sobre objetivos más importantes, sobre recursos a utilizar, distribución de tiempos, etc., puede ser una situación formal e informal en la que los profesores aprenden:

Nosotros hacemos programa común y examen común, que no siempre es fácil porque lo que decía, ya todos somos mayores y cada uno tiene un reino de Taifas... ¿ipero cómo vas a poner eso?, ¿de verdad crees que eso es lo importante?; y a base de mucho ajuste, de mucho esfuerzo, de mucho desgaste, de mucha reunión...; pero a mí me gusta... y conseguimos hacer programa común, bibliografía común, después cada uno...; claro está, se arma el esqueleto y después cada uno lo explica como mejor le parezca. Siempre hay alguien que dice: pues yo no quiero participar en este programa; bueno, pues hay que aceptar la diversidad,... tiene su propio programa. Pero es la excepción. Y yo aprendo mucho. Cosa que te parece que es la clave, y discutiendo piensas, pues efectivamente, porque no expliquemos esto como un epígrafe concreto... da igual, no pasa nada.

Seguramente ello no es ajeno al hecho de que Maricruz es la Coordinadora de las materias a las que se refiere.

\section{Dar a la Universidad de Sevilla una dimensión europea. Creando cultura}

Por otra parte, en esos años la Universidad también tiene que buscar la integración en Europa. Y ello le obliga a comprometerse con funciones institucionales. Su primera responsabilidad fue el programa Erasmus. Eran pocos aún los programas que existían en la Universidad y se gestionaban a través de redes de universidades. Se hizo cargo de este programa en la Facultad de Derecho en el curso 1988-89, en que se inicia, a propuesta del Profesor Carrillo Salcedo (gran jurista, que ha sido miembro del Curatorium de l'Académie de Droit International de la Haya y de la Comisión Europea

\footnotetext{
${ }^{5}$ En nuestro trabajo Estebaranz, A. y Mingorance, P. (2003) ¿Qué papel juegan los Departamentos en el Desarrollo profesional de los Profesores de Secundaria? Profesorado. Revista de Currículum y Formación del Profesorado. Vol. 5, № 1, pp. 67-91, habíamos visto la influencia de los compañeros en el aprendizaje de los profesores a través de actividades de comunicación formal e informal.
} 
de Derechos Humanos; además trabajaba como Magistrado del Tribunal Europeo de Derechos Humanos en el periodo 1986-1990).

\section{Demostrar competencia; pero... tener el reconocimiento de hombres poderosos $^{6}$}

Marycruz desempeña esta función con éxito. El programa funciona bien, y la Universidad percibe el sentido de futuro de estas acciones, por ello, el Vicerrector de estudiantes, Ricardo Huete, le propuso colaborar más con el Rectorado para montar otros programas, en concreto los P.I.C. (Programas de Cooperación e Intercambio) que se desarrollaban a través de una red en la que participaba la Universidad de Sevilla junto con Estrasburgo, Dublín, Turín, Nuremberg y Lisboa. No tenía responsabilidad en ellos, pero colaboraba. Colaboraba también impartiendo Conferencias en otros programas europeos como el Adapt, dependiente de la Consejería de Trabajo y Desarrollo Tecnológico, para situar el Marco Europeo de los Programas de Formación Profesional Ocupacional. Es una constante la participación en cursos o Seminarios organizados por otras Universidades o Instituciones, a las que le invitan y a las que ella responde.

En el año 2000, con una situación familiar "curiosa", un niño de tres años y una niña de meses, le llamó el Decano de Derecho, M.R. Alarcón, al que había dicho durante años que hacía falta una persona responsable de Relaciones Internacionales. Los programas habían evolucionado muchísimo y ya no era suficiente la atención que ella podía prestarle. De hecho, tenía un despacho individual por "lo molesta" que resultaba a los compañeros, dadas las visitas continuas de sus alumnos y de los estudiantes de otras Facultades que iban a preguntarle. Le llama para decirle que ha comprendido, "me has convencido", que es necesario crear un Vicedecanato de Relaciones Internacionales y que considera que ella es la persona idónea.

Era el momento en el que Marycruz había planteado al Consejo de Departamento su intención de prepararse para optar a Cátedra, y por ello la necesidad de que la relevaran de unas funciones que le ocupaban mucho tiempo, que había desarrollado con gusto, pero que podían ser desempeñadas por otra persona durante el periodo siguiente. Por ello, le expresa su deseo de consultar con su Departamento, su maestro y su grupo de trabajo. Siempre está por delante la necesidad institucional.

Durante el plazo de una semana que se tomó para decidirlo, recibió la llamada del Rector, Miguel Florencio:

Subí las escaleras temblando, pensando que había hecho algo mal. No tenía ninguna relación con él, y mi participación en el Claustro había sido muy puntual, más bien poca.

Justamente le proponía encargarse de la Dirección de Relaciones Internacionales, -que hasta el momento dependía de Relaciones Institucionales- como de una Dirección autónoma, no dependiente de ningún Vicerrectorado. En su concepción, debía tener las atribuciones de un Vicerrectorado aunque sin este título porque no cabían más Vicerrectorados. ¿Se le habría pedido a un hombre valioso, y considerado como tal para desarrollar una función, que la ejerciera, que hiciera el trabajo, pero sin el

\footnotetext{
${ }^{6}$ Wirth, L. (2002) Romper el techo de cristal. Las mujeres en puestos de dirección. Col. Informes OIT, № 58, Ministerio de Trabajo y Asuntos Sociales de España.
} 
nombramiento de la categoría correspondiente? Y en este caso, ¿lo habría aceptado ese hombre? La respuesta de Marycruz es la misma: Tengo que pensármelo. Pero consulta a su maestro, que tiene la respuesta inmediata: "Esas cosas no se piensan, se aceptan". Es la oportunidad de hacer crecer la Universidad en una línea que ellos tienen clara, la dimensión europea. Y acepta ser Directora General de Relaciones Internacionales, después de comunicarle al Decano de Derecho la nueva situación, que ya daba un giro a la gestión de los programas internacionales de toda la Universidad.

El trabajo en el Rectorado me encantaba. Veía que podía hacer real lo que pensaba a nivel teórico. Llevaba 17 años trabajando relaciones internacionales, desde 30 de carrera. $Y$ ves que puedes ponerlo en marcha, y que lo que has sembrado con los programas Erasmus, se puede multiplicar de manera exponencial".

Se movía en un terreno cómodo en el que sabía de qué iba todo; era su dominio de conocimiento. Ello suponía trabajar en inglés y en francés, pero ella dominaba también esas competencias.

En enero de 2004, el Vicerrector de Relaciones Institucionales y Extensión Cultural, Adolfo González, cesa en el cargo para pasar a la política nacional. Como en junio había elecciones a Rector, se le pidió que ocupara el cargo de Vicerrectora; pero entonces el Vicerrectorado se amplía: Relaciones Institucionales, Relaciones Internacionales y Extensión Cultural: Una Hectárea del Rectorado. Además no dejó la docencia, que es su gran motivación, y una función de gran impacto para sus objetivos, para no desconectarse del mundo. Tiene en ese momento una hija de dos años, otra de cinco y un hijo de siete años.

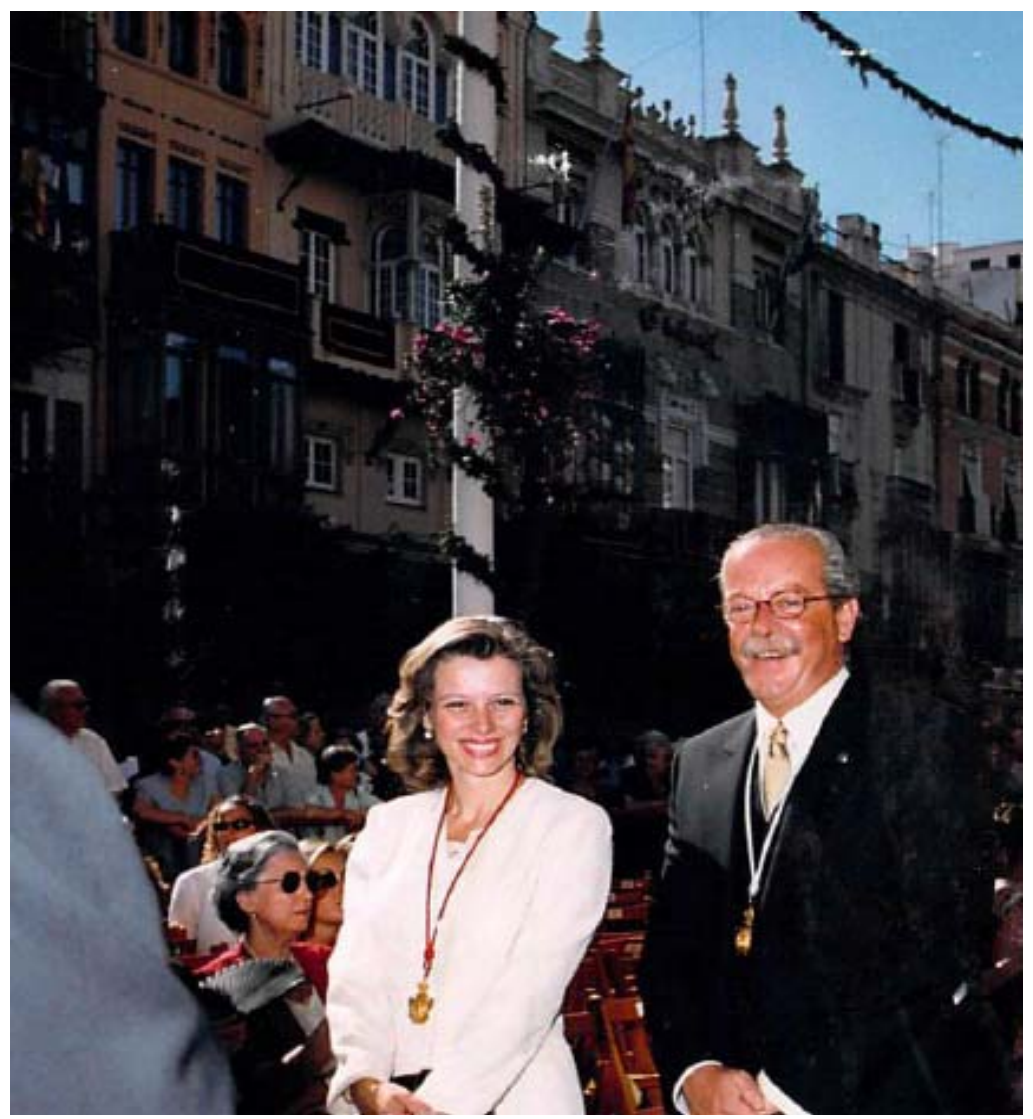

En la procesión del Corpus, con el Vicerrector Adolfo González. 


\section{Integrando las tres funciones}

La gestión de la Universidad exige liderazgo. La mayoría de los cargos de responsabilidad en la Universidad suponen una preocupación intelectual diferente a la propia especialidad. Por una parte, está la investigación, que en el caso del equipo rectoral disminuye a favor de las responsabilidades de gestión; la docencia, así mismo, cede parte de su tiempo; y por otra parte están las tareas de organización, dirección y control de las diversas actividades institucionales.

Pero el caso del Vicerrectorado de Relaciones Institucionales, Internacionales y Extensión Cultural es peculiar. Porque se crea, desde el conocimiento de las tendencias de futuro en cuanto a la integración de los países en la Unión Europea y la necesidad de una formación orientada con visión Internacional, tal como concibe Marycruz.

Mi objetivo primordial es abrir puertas a los futuros profesionales. Es la razón de mi estudio, de mi formación, de mi investigación, de mi docencia y de mi gestión universitaria: Por fin puedo hacer lo que pienso y lo que sé que hay que hacer, y lo que enseño.

Probablemente ésa es una de las razones de sus éxitos. Gobierna, planifica y gestiona, lo que conoce y lo que le apasiona ${ }^{7}$. Considera importante anticiparse a una sociedad que está cambiando hacia la integración y que hay que prepararla para ella. Marycruz lo sabe mejor que nadie. Es su especialidad. Y por ello su responsabilidad. Su responsabilidad lo primero:

Tengo esa responsabilidad con mi Institución, a la que amo y a la que hace falta que todo el profesorado así como el personal no docente ame más, se identifique más con ella.

\section{Liderazgo compartido}

Ahora bien, es un Vicerrectorado que exige la gestión de tres equipos diferentes. Relaciones Institucionales era un Vicerrectorado General, nuclear en la Universidad, con el que había trabajado de manera muy estrecha. Ambos (Relaciones Institucionales y Relaciones Internacionales) eran unos órganos que se responsabilizaban de temas transversales, a veces difíciles de separar. Al ser tan amplia la tarea, el mismo Rector le propone nombrar como Directora de Relaciones Internacionales una persona con la que pueda colaborar fácilmente; repartir el trabajo sin las dificultades de tener que explicarse y esperar a que se comprendan bien las tareas y los objetivos, las ideas en definitiva. $Y$ tiro de la persona con la que siempre he contado: Eulalia Petit, una persona extraordinaria, en su valoración, que era la responsable de Relaciones Internacionales en la Facultad de Derecho. Conocía bien el campo. Tenía la misma especialidad y había seguido los mismos pasos que Marycruz.

Eulalia sabía que cualquier cosa que hiciera la podía firmar yo, y también sabía que si yo pensaba algo ella estaría de acuerdo conmigo.

\footnotetext{
${ }^{7}$ Davenport, T.H. (2006). Motivar, retener y crear valor en la Era del Conocimiento. Ediciones Deusto. Barcelona.
} 
Es el ejercicio real del liderazgo compartido, tan defendido en las teorías organizativas actuales ${ }^{8}$, y que según la literatura especializada se encuentra en más ejemplos de mujeres que de hombres. Aunque también existe algún ejemplo de sintonía y apoyo incondicional de hombres, y específicamente en el Rectorado de esa etapa. En su opinión, es posible el liderazgo compartido con una persona que tiene el mismo nivel de preparación, la misma visión y una fuerte relación de amistad, que facilitan la confianza total en el desempeño de las funciones que delega en ella, "siendo consciente de que si algo sale mal, yo soy la cabeza responsable". Pero también es importante considerar que se trataba de un nombramiento nuevo que dependía de ella.

En las otras dos áreas, los responsables de la gestión continúan. Habían sido nombrados por un Vicerrector, hombre. Extensión Cultural era un área con más dificultades de actuación integrada. Trabajar con mujeres tampoco es garantía de unidad y de trabajo en equipo. Y se produce el cambio de la Directora de Promoción Cultural, así como el cambio del Director del Servicio de Publicaciones. La cuestión es que la selección de personal para puestos directivos es una tarea delicada e importante. La destitución de un cargo responsable es una decisión de las más difíciles de la gestión universitaria; pero en todo caso se produce porque la Vicerrectora está informada, hay visión, y capacidad resolutiva.

Mantenerse informada de cómo se desempeñan las funciones delegadas es otra característica que la bibliografía sobre liderazgo reconoce en las mujeres ${ }^{9}$. En este caso es tan manifiesto su interés, que al día siguiente de la muerte de su padre llama por teléfono a la persona responsable de un acto público, correspondiente a un programa europeo, para informarse sobre el desempeño de la representación de la Universidad en él.

\section{¿Qué aporta Marycruz Arcos Vargas a la política universitaria?}

Sin duda alguna, liderazgo, por su alta motivación, integrando la razón y la pasión, que contagian ilusión multiplicando las acciones emprendidas en una línea de iniciativas. Su iniciativa, tiene como resultado la innovación en la institución, que en realidad es una creación, porque no existía apenas la idea y la acción orientada a construir la Unión Europea. Estar presente, informarse e informar, difundir, propiciar el conocimiento y las acciones informadas por el espíritu del Tratado de la Unión Europea y ajustadas a Derecho, así como formar a profesionales de distintas especialidades y de diferentes edades, mayores y jóvenes, a través de los Masters.

Al valorar su gestión se siente orgullosa de su aportación al cambio en la Universidad:

Se ha internacionalizado la Universidad. Y no tanto por el proceso de Bolonia, que nos viene dado, cuanto por lo que se ha ido creando.

\footnotetext{
${ }^{8}$ Kouzes, J. y Posner, B. (2002) Las lecciones del pasado y del futuro. En Bennis, W. y otros (eds) El futuro del liderazgo. Bilbao, Deusto. Cap. 7, pp. 93-103.

${ }^{9}$ Goleman, D. (2002) El líder resonante crea más. Barcelona, Plaza\&Janés.
} 
Cuando empezó con la Dirección de Relaciones Internacionales era una oficina con poca actividad, pocos estudiantes participaban en programas europeos (alrededor de 100), y ha llegado un momento en que los alumnos se mueven de mil en mil

La Universidad de Sevilla se ha puesto en el mundo. Se conoce lo que hace. Era una buena universidad, pero bastante cerrada, y ahora se conoce y se sabe lo que estamos haciendo.

Además, se ha creó el Plan Propio de la Universidad de Sevilla aumentaron los programas de Cooperación, Sócrates, Leonardo da Vinci; los Intercampus; las Becas para alumnos para estudiar en Universidades Norteamericanas, para Profesores, etc.

\section{Aprovechar los rayos de luz, y convertir los obstáculos en oportunidades}

Las iniciativas que se pusieron en marcha desde el Vicerrectorado Internacionales en 2002 han tenido un desarrollo espectacular que podemos entender a través de las propias palabras de Marycruz al responder a nuestra pregunta sobre el impacto de los contactos que establecieron con otros países y con otras universidades.

$¿$ ¿e dónde surge la idea del viaje a China -un hito en este proceso- que realizaste con la Ministra Mercedes Cabrera, el presidente de la Conferencia de Rectores (Ángel Gabilondo) y la Rectora de Málaga? Y ¿qué relación ves con el desarrollo de Andalucía Tech y con el Instituto de Estudios Orientales?

iTanta relación con otras universidades, no solamente con China!... iLo que sembramos! Ahora se ven los resultados. Eso fue de repente, abrir una puerta y decir: Aquí hay cosas, no solamente desde el punto de vista comercial... vamos a vender nuestra Universidad allí para que vengan alumnos aquí con China, que también... dinerito, pero eso sobre todo con Brasil. Los brasileños decían que les era más barato mandar estudiantes brasileños becados a estudiar a Europa que abrir nuevas universidades; y entonces, que les dijéramos dónde teníamos hueco para mandarnos a sus estudiantes... Pero bueno, son países emergentes a los que les podemos abrir las puertas de nuestra Universidad, y nosotros beneficiarnos también. Pero se abre todo un desarrollo de un mundo en el que, creo que no especialmente Sevilla,... Occidente estaba cerrado; no teníamos en cuenta que existía un mundo inmenso, inmenso... todo lo que son los estudios orientales... no ya estudiarlos a ellos, sino compartir con ellos otra manera de ver el mundo, de ver todas las ciencias... yo creo que lo importante era eso...

Cómo aprendimos de cualquier cosa..., porque pasamos muchas horas juntos, muchas horas de avión... y fue el momento; lo mismo que unos años antes, en 2002, fue el momento de abrir nuestra Universidad a Europa, fue el reventar del Plan Bolonia. Tuvimos la buena suerte de mi licencia por maternidad, dije esto ya no puede ser cosa de Relaciones Internacionales, esto es de Ordenación Académica y entonces pasé todos mis papeles de lo que era el Plan Bolonia a ese Vicerrectorado, y a partir de ahí cambiaron las Titulaciones y tenemos el Grado. Por eso te digo que lo que son las coincidencias... En 2008 ya el Este no es lo que está detrás del telón de acero, que se había caído en 1989. Ya tenemos que mirar al Este que es Oriente, que es otra manera de enfrentar los problemas, la vida, lo cotidiano, nos guste o no nos guste. Y fue de las primeras relaciones. Aunque Sevilla lo aprovechó relativamente poco en los primeros momentos. Hubo Universidades que se embarcaron más: Málaga fue de las primeras que empezó a desembarcar... Pero es importante que recogimos aquel rayo de luz... 
Llega una convocatoria al Vicerrectorado, donde llegan todos los días 27 convocatorias de reuniones, "todas importantísimas para revolucionar el mundo". Esta era una que venía de la embajada China en Madrid. Venían representantes de las Universidades chinas que querían tener contacto con universidades españolas, y a mí me pareció que podía ser importante. Lo comenté con Eulalia Petit: ¿Por qué no vamos y escuchamos y vemos lo que hay? y decidimos ir... Nos fuimos y cogimos esa línea en las Relaciones Internacionales, que ahora se ha desarrollado en el Grado de Estudios Orientales.

Pero también "cogimos otra línea", dice, la del Pacto Mundial que se fue a firmar con Kofi Annan (7은 Secretario General de Naciones Unidas de 1997 a 2006).

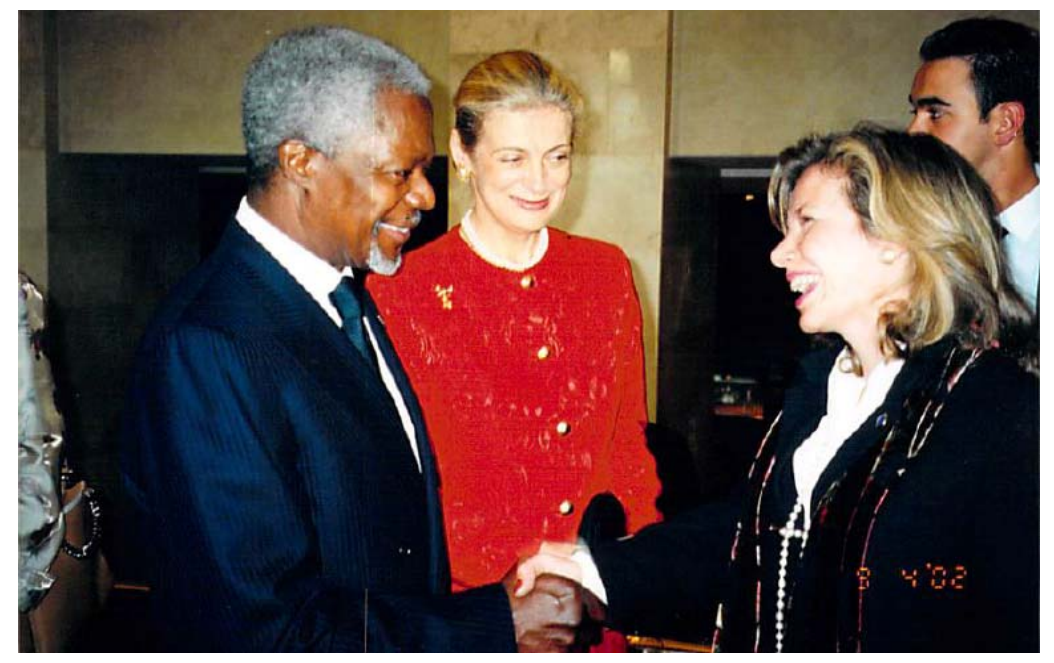

Marycruz considera que aquello fue importante para la Universidad:

Era la primera experiencia de Responsabilidad Social Corporativa a nivel Internacional una iniciativa de Naciones Unidas donde firmaban las empresas del Ibex 35 y nos invitaron a unas cuantas Universidades, no sé si a todas, pero a Sevilla la invitaron, y yo dije: allá que me voy. Sevilla firmó. Firmó Córdoba, que tenía una Vicerrectora que era magnífica, y después se diluyó un poco el trabajo que se había iniciado.

Cuando vamos viendo la vicisitudes de esta apertura a las Relaciones Internacionales en unas universidades y en otras, nos llama la atención un dato: en el caso del desarrollo de Andalucía Tech, Campus de Excelencia Internacional, que se implanta y se desarrolla en Sevilla en alianza con la Universidad de Málaga, destacando la captación de talentos (profesores y alumnos), las titulaciones conjuntas en áreas estratégicas del Proyecto, y la Escuela Internacional de Postgrado, hay tres mujeres responsables: la Rectora de Málaga (desde 2004), y las dos Vicerrectoras de Relaciones Internacionales de Sevilla, que se responsabilizaron de un Proyecto que aglutina las fortalezas y capacidades del sistema Ciencia, Tecnología y Empresa.

En 2008 se produce el cambio de Vicerrectora. Tuvimos mucho interés en preguntar sobre cómo se traspasa el poder, que es sobre todo comunicación valiosa y no sólo el hecho de proporcionarle la información a la persona que va a desempeñar el cargo en adelante. Hay dos factores que nos parecen importantes en el mantenimiento de estas relaciones internacionales: la permanencia de las personas que tuvieron la iniciativa, que en el caso de Málaga parece claro, y el hecho de que el cargo de relaciones sea desempeñado por mujeres y traspasado a mujeres. Los párrafos siguientes son muy expresivos: 
Aquí hemos tenido suerte porque todos esos empujones que dimos salieron para adelante. Con Lourdes Munduate fue muy fácil desde el principio conectar. Tuvimos una reunión larguísima Eulalia y yo con ella, y le estuvimos dando información: Gente con la que no debes dejar de hablar, que cuando te llamen aquí, me parece que hay algo (China), "porque hay cosas que son puro humo..."

India, no dejes de mirar a India, nosotras no hemos llegado, pero India es un desafío. Además India tenía de embajadora una mujer que tenía mucha iniciativa, proyectos de microcréditos; estaba abriéndose muchísimo y Lourdes siguió en esa línea.

Después hubo iniciativas que han quedado un poco más paradas, como el grupo Tordesillas. Que es una reunión de Universidades europeas y brasileñas que gestionaba Valladolid, pero que cuando pasó la gestión a otra Universidad parece que se paralizó...

Nos preguntábamos cuál es el futuro de la Universidad, y parece ser que va en esta línea. Innovación que se basa en la creación de conocimiento, relación con otras empresas e instituciones a nivel local, nacional e Internacional. Pero todo eso está en marcha como producto de diversas iniciativas generadas en el seno de una institución o atrapadas dentro de la red de relaciones en las que se mueve una Universidad. Y se necesita apoyo, que no es tanto la inversión. Aunque sí que hace falta voluntad.

Nos movemos muchísimo, y todavía tenemos que movernos más: Ya te mandaré las nuevas propuestas de nuevos diseños en esta línea. Nosotros tuvimos una época muy buena, de iniciativas, como las iniciativas culturales..., hay algunas de las que estoy muy orgullosa, como el fomento de la lectura..., creo que es esencial. Eso costaba poco dinero... Bueno, sí, aquí costó dinero mi viaje a China; no te digo que fuera barato, aunque es verdad que no íbamos al lujo asiático, pero... nosotros contábamos con medios, ahora mismo con los recortes ..., recortes, recortes, no es que no se puedan hacer cosas pero hay que echarle un poquito más de imaginación. Hay que sacarle los dobladillos..., pero con lo que hay se pueden sacar dobladillos...

Actualmente -2012-, en la Universidad de Sevilla se desarrollan dos Planes propios, uno de Relaciones Internacionales y otro de Cooperación al Desarrollo. El crecimiento de estos programas es un hecho. Se la reconoce como una Universidad líder en programas de movilidad con 4.000 estudiantes internacionales; galardonada en 2010 por el Organismo Programas Educativos Europeos por la gestión del programa Erasmus, que Marycruz siente como suyo porque disfruta de los logros de su Universidad: Nos han dado un premio por lo bien que lo hacemos en la Universidad de Sevilla... También se la reconoce como excelente en la Cooperación al Desarrollo con proyectos premiados internacionalmente en actuaciones con América Latina, Asia y África. El impacto es imparable, porque hubo liderazgo y porque ha habido continuidad.

Marycruz es una líder de la innovación por la seguridad en los criterios, y por su forma de ser y de actuar, que define un estilo de gestión muy propio de mujeres líderes $^{10}$, basado en el convencer y no imponer. Son sus palabras:

Mi capacidad de liderazgo reside en los criterios, y que convenzo. Nunca mando, nunca impongo, convenzo. Hay a quien no le convenzo nada. No intento que todo el mundo entre por mi vereda. El que entre es porque lo he convencido.

${ }^{10}$ Estebaranz, A. (2004) Observatorio e-igualdad. Diputación de Córdoba. 
Ello supone capacidad de relación, tan necesaria cuando se entiende que es preciso tomar decisiones por consenso, y desempeñar las funciones trabajando codo con codo con las personas de su equipo ${ }^{11}$. Aunque si un equipo no funciona entiende que hay que cambiarlo, sin eludir la propia responsabilidad. Lo cual exige la capacidad de comunicación, que ella tiene. Comunica porque sabe comunicar. Tiene capacidad y tiene algo importante que comunicar. Y porque se cree lo que dice. Por eso convence. Es su mayor competencia para dirigir equipos y para formar parte del equipo rector de la Universidad, como ella misma reconoce. Pero, además, como Vicerrectora de Relaciones Institucionales, era la responsable de la comunicación institucional, ya que el Gabinete de Prensa también depende de Relaciones Institucionales. La Universidad tiene criterios, tiene postura ante el mundo, realiza actividades, participa en la sociedad, y es preciso saber comunicar lo justo y lo que es conveniente, es una habilidad y una responsabilidad importante.

Es una líder cercana, con una gran disponibilidad para entender y orientar cualquier problema de gestión de programas. Incluso para el profesorado que no pensaba votar al Rector de cuyo equipo rectoral formaba parte. Su agenda siempre estaba llena de visitas. Por las actividades que coordinaba, y por su capacidad de acoger a las personas. Son las mismas capacidades que usaba para la participación en el equipo rectoral.

Me he sentido cómoda y he descubierto que el mundo es muy plural, no todos piensan como yo, pero en determinadas cuestiones y situaciones pueden encontrarse puntos de convergencia. Hemos aprendido muchísimo.

Por ello, también tiene capacidad para representar muy dignamente a la Universidad. Durante la época de Directora del Secretariado de Relaciones Internacionales y de Vicerrectora, parte del trabajo y de la responsabilidad consistía en representar a la Universidad en actos públicos, políticos, empresariales, culturales, universitarios, etc. Y lo hace mostrando su cara más amable, con elegancia, encantada de hacerlo. Sabiendo muy bien lo que suponen las Relaciones Institucionales que ella ha impulsado, abriendo la Universidad al mundo, a la sociedad de su entorno y a la sociedad internacional.
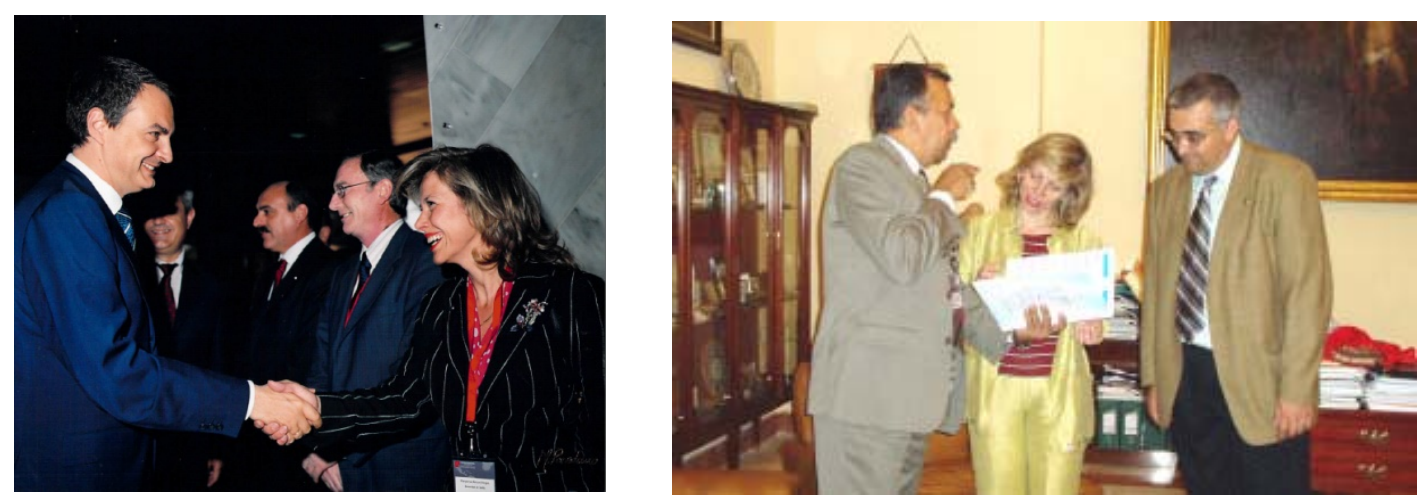

Marycruz en actos institucionales. Saludando al Presidente del Gobierno junto a otros compañeros de Rectorado, a la izquierda. En la foto de la derecha aparece, como miembro del Comité Organizador del I Encuentro de Rectores Iberoamericanos, comentando la propuesta de Convenio Marco que ella misma ${ }^{11}$ Blackmore, J. (1999) Troubling Women. Feminism, Leadership and Educational Change. Philadelphia,
Open University Press. 
facilitó para ser revisado con el Dr. Juan Ramón de la Fuente, Rector de la Universidad Autónoma de México (UNAM), y el Prof. Antonio Ramírez Arellano, Vicerrector de Postgrado de la Universidad de Sevilla (Rector actual); en el Convenio se contempla el intercambio de líneas de investigación, becas para estudios de Doctorado, etc. (2007).

Hay que señalar la capacidad de trabajo constante. Algo que comparte con otras mujeres directivas. La capacidad de cumplir objetivos en su momento. De llegar a tiempo. Su Vicerrectorado era "una macroárea" que multiplicaba los trabajos y los frutos. ¿Cómo se podía llevar adelante la cantidad de trabajo que generaba? ¿Cómo se puede atender a tantas demandas a la vez? Con tiempo y trabajo.

Eso se hace con muchas horas de trabajo cada día con mucha concentración, y asumiendo que tienes que hacer las cosas a medias, y a mí me gusta ser una mujer 10, pero no puedo dedicar todo mi esfuerzo a la investigación, o a preparar mis clases, o a mis hijos, o al Vicerrectorado.

Repartir el tiempo significa asumir que quizá se hagan cosas a nivel de cinco, pero se hacen.

Yo hablo con mis hijos, les comento estas ideas, les leo el periódico, comentamos las noticias, y eso lo puedo hacer porque le presto menos atención a otras cosas.

Desde luego teniendo muy claras las prioridades de cada situación: Criterios e inteligencia intuitiva, una forma de inteligencia que actúa seleccionando la información relevante de cada situación de forma inmediata y eficaz, sin necesidad de un análisis detenido en un momento dado para tomar una decisión adecuada ${ }^{12}$; que aún no es suficientemente valorada, socialmente, por desconocimiento o porque domina aún una forma de pensar y decidir más masculina.

La opción de llevarse trabajo a casa es problemática. Es cierto que Internet puede facilitar la conciliación, pero también puede ser un obstáculo,

...porque al final mezclas y te crea estrés estar pensando que tendrías que abrir el correo y no puedes, o que tendrías que prestarle mejor atención a tus hijos.

Además es un Vicerrectorado que exige presencia en muy diferentes actos culturales, científicos, sociales y empresariales, con horarios bien diversos. Y la pasión por la tarea hace que en su mente siempre estén los temas que debe resolver.

Hacer las cosas bien es un valor que aprendió en su formación y que forma parte de la responsabilidad que le caracteriza. Pero teniendo que compaginar tantas actividades a la vez, aprendió, con Golda Meir, que no pasa nada por no hacerlas perfectas, pero sí es un problema dejar de hacer algunas que son tu responsabilidad. Es la mujer que se hace fuerte teniendo claras sus prioridades. Y valorando los logros. Lo cual es muy importante, porque la culpabilidad y la crítica implacable que nacen de la responsabilidad excesiva pueden conducir a la paralización. Nada más lejos de un Vicerrectorado joven que ha multiplicado de manera bien patente, por ejemplo, la participación de estudiantes en los programas europeos de movilidad para la formación.

12 Gladwell, M. (2005) Inteligencia intuitiva ¿Por qué sabemos la verdad en dos segundos? Madrid, Santillana. 


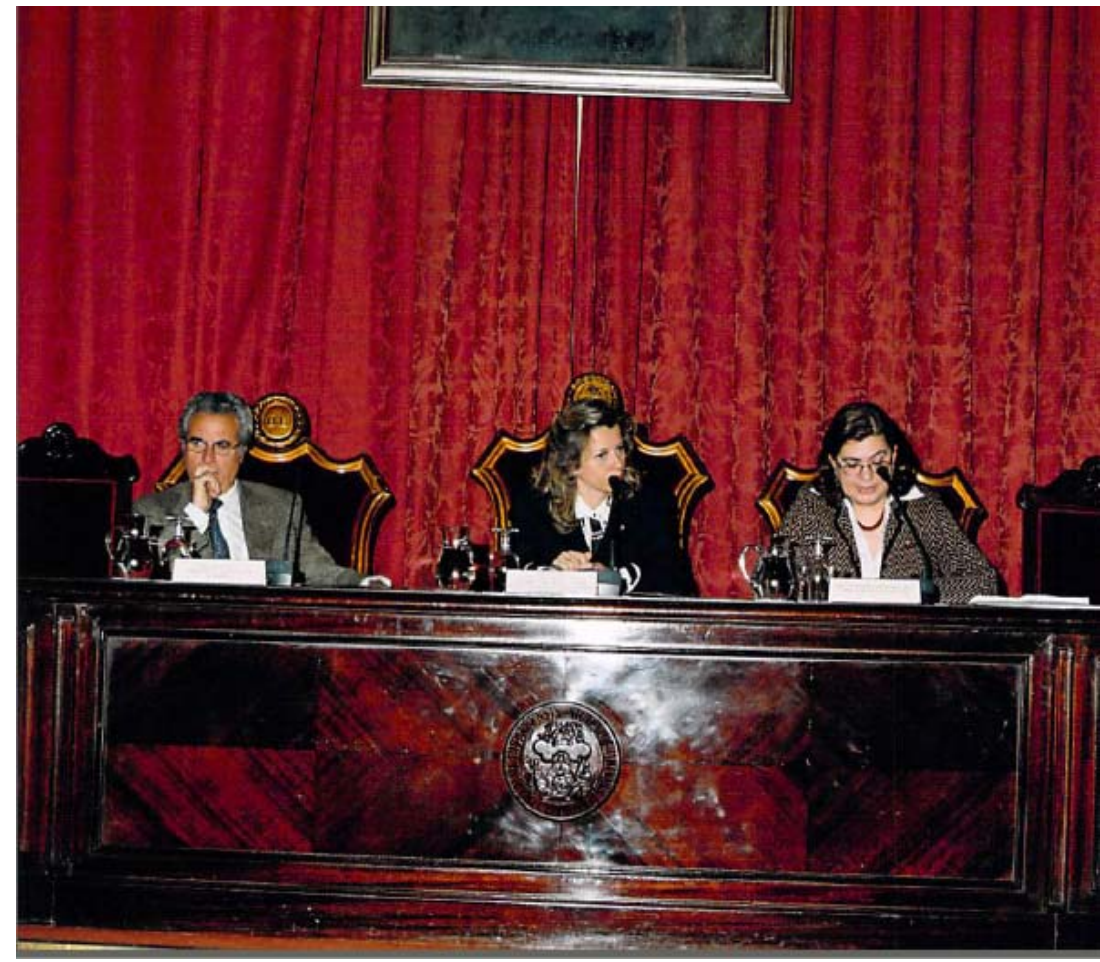

Presidiendo el homenaje a Neruda en el paraninfo de la Universidad.

\section{8 abre una nueva etapa. ¿Por qué deja el Vicerrectorado?}

La gestión ha ocupado muchos esfuerzos y muchos tiempos, en momentos especialmente importantes en su casa: el cuidado de sus hijos pequeños, el nacimiento de su hija pequeña, cuando ya es Directora General de Relaciones Internacionales, la muerte de su padre... Pero no se queja. Había que hacer ese servicio y lo hizo durante unos años. Es preciso rotarse en los cargos de la Universidad: "Ocho años de responsabilidad en la gestión universitaria son suficientes". También entendía que para la Universidad era bueno el cambio: "Yo llevaba muchos años viviendo hacia fuera, ya estaba muy vista. Hacia falta renovación". Es otra característica del liderazgo femenino, la consideración del poder como función temporal de servicio a la comunidad. Una concepción diferente sobre el poder que las mujeres aportan ${ }^{13}$. Con el actual equipo y con el Rector actual tiene una relación magnífica. Ahora bien, el trabajo es muy importante pero no lo es todo:

"Tengo mi vida personal y quiero vivirla también".

La carrera profesional sigue y hay que retomar aspiraciones normales de todo universitario: conseguir llegar al máximo de categoría profesional. En el año 2000, salió a Concurso Oposición una cátedra en la Universidad Pablo de Olavide (Sevilla) con su perfil profesional. Y firmó la solicitud. Pero no podía presentarse porque estaba por delante su compromiso con el Rectorado. Había aceptado la Dirección de Relaciones Internacionales. ¿Exceso de responsabilidad? En todo caso elige según sus valores, como siempre. Abandonó temporalmente el camino hacia la Cátedra por responder a

\footnotetext{
${ }^{13}$ Wullich, M. (2004) 6 mujeres 6 voces. Otra mirada sobre la mujer y el poder. Madrid, Síntesis.
} 
las demandas institucionales, y ahora quizá haya llegado otra etapa en la que poder dar más tiempo a la investigación y a publicaciones en Revistas "exigidas para la Acreditación"...

Pero sin abandonar la gestión porque puede y le gusta. Actualmente es Directora del Centro de Documentación Europea. Sus comentarios vuelven a revelar su persona: No magnifiquemos. Es una Biblioteca especializada.

Es un Centro dentro de la Universidad que se crea por la participación de la Comisión Europea, la Junta de Andalucía y la Universidad de Sevilla, que financian la supervivencia. Pero la visión de Marycruz es que su función es sacar partido a la documentación oficial disponible. Es poner a disposición de los usuarios, no solamente universitarios, un servicio de consulta sobre cualquier temática relacionada con la Unión Europea. Poner en valor para la sociedad, desde la comunidad universitaria, lo que se está haciendo en temas europeos. Ella recalca que no debe ser solamente de Derecho Europeo. Por ello los proyectos son diversos. Se organizan con la Junta de Andalucía cursos sobre materias europeas para los funcionarios, jornadas, seminarios, coloquios, en temas relevantes para la Universidad y para otras personas e instituciones. Las ocasiones aparecen a raíz de la actividad de la Comisión Europea. Por ejemplo, en 2008 habían previsto actividades formativas sobre la "Directiva de servicios", que puede tener mucho desarrollo para el mundo empresarial; o sobre las cercanas elecciones al Parlamento Europeo, en el que es importante que se participe, y la Universidad tiene su responsabilidad en ello.

Podríamos ser el guardián de la Documentación, pero esto debe ser un punto de información y difusión de ideas europeas

La Universidad, debe ofrecer el conocimiento que produce y que atesora para que pueda utilizarlo la sociedad; al final es otra aportación al cambio social. De hecho, en este momento de paro (2012) hay dos tipos de documentación destacadas en la página web del Centro de Documentación de la Universidad de Sevilla: "Oportunidades de trabajo en la UE": oposiciones, contratos, prácticas; y "Oportunidades de Formación": estudiar, viajar y trabajar en Europa.

Es una actividad más reducida, un equipo de trabajo más pequeño (cinco mujeres y un hombre) pero también una cierta continuidad en el tipo de aportación: Contribuir a la formación con enseñanzas sobre la integración europea en la Universidad, que desde el Año 2000 promueve la Comisión Europea, a través de la Acción Jean Monnet, sabiendo la importancia que ello tiene para la construcción europea, y específicamente coordinar "los seminarios, jornadas e investigaciones que se realicen en el marco de las actividades programadas por los Catedráticos Jean Monnet" ${ }^{14}$.

Cuando se le pregunta qué siente al ver que en la siguiente legislatura (20082012) su Hectárea se ha dividido en tres Áreas, responde con rapidez y una sonrisa sincera:

Orgullo. Se ha reconocido el volumen de trabajo y la importancia de un Vicerrectorado que aglutinaba intereses importantes, y en los que hemos crecido.

\footnotetext{
${ }^{14}$ http://www.centro.us.es/cde/
} 
Reconocemos el valor de la puesta en práctica y en valor de una idea, innovadora para España, que germinó gracias al esfuerzo de unos pocos estudiantes predoctorales muy buenos, que bebieron del entusiasmo por los Derechos Humanos y el Derecho Europeo de grandes juristas. Es el valor de la formación, la generación del cambio de la realidad por la profundización y puesta en práctica de una idea poderosa, y la multiplicación de los efectos.

En el Programa electoral del nuevo Rector ${ }^{15}$ para 2012-2016, leemos como objetivos la Internacionalización de la Universidad, la contribución a la riqueza y al empleo por la transferencia del conocimiento, la apuesta por la cultura, o la comunicación como estrategia..., también favorecer la igualdad de oportunidades, entre otros. Pero ciertamente estos objetivos y principios de futuro son el desarrollo de lo que se comenzó a generar y desarrollar en el Vicerrectorado de Relaciones Internacionales en 2003.

Marycruz hoy crece como crece la Universidad. Los proyectos Internacionales aumentan y se imbrican en la formación de los estudiantes. Crecen las prácticas en Empresas dentro del programa Leonardo, crecen las prácticas de Inserción Laboral, y crecen los Convenios de colaboración con empresas para promover la Transferencia Tecnológica (en 2012 son más de 900). La dimensión Internacional lleva a Proyectos de Investigación y de Formación conjuntos, a las convocatorias de becas en colaboración entre la Universidad y los Bancos, entre la Universidad y algunos países como Japón... Continúan la becas Fulbrigth, las ayudas para estudiar en Estados Unidos, las becas del Programa Intercampus creadas por el acuerdo de 15 países de la América Latina con España (1994).

Y crecen las Cátedras patrocinadas por Empresas o Fundaciones. En 2011 son 26 las que desarrollan su actividad como "medio de promocionar las relaciones entre las empresas y la vanguardia de investigación y el conocimiento generados en la Universidad"... Contribuyen también a la formación de futuros profesionales en las Áreas de trabajo e investigación de interés de la cátedra y a la formación continua de los profesionales ${ }^{16}$. Contribuyen, además, al enriquecimiento del conocimiento disponible en un campo a través de la difusión de los resultados, en el marco de las condiciones de publicación de los mismos establecidas en los Convenios.

Como Directora del Centro de Documentación Europea, Marycruz colabora con empresas en las Prácticas de Formación Académica y en las Prácticas de Postgrado, Máster y Doctorado. Y específicamente con el Vicerrectorado de Transferencia Tecnológica a través de la dirección (codirección) de la Cátedra de Política de la Competencia; una Cátedra interdisciplinar fruto del Convenio Marco de Colaboración entre la Agencia de Defensa de la Competencia de Andalucía y la Universidad de Sevilla que desarrollan en colaboración la Facultad de Económicas (Dr. Luis Palma), con dos Departamentos implicados, y la Facultad de Derecho; "creada por dos años, con el fin de promover el análisis, investigación y docencia sobre defensa y promoción de la competencia, así como sobre los aspectos jurídicos y económicos del funcionamiento competitivo de los mercados, desde todos los puntos de vista que se estimen relevantes".

\footnotetext{
${ }^{15}$ Proclamado Rector electo por el Claustro Universitario en sesión de 23-II-2012.

${ }^{16}$ http://vtt.us.es/catedras/
} 


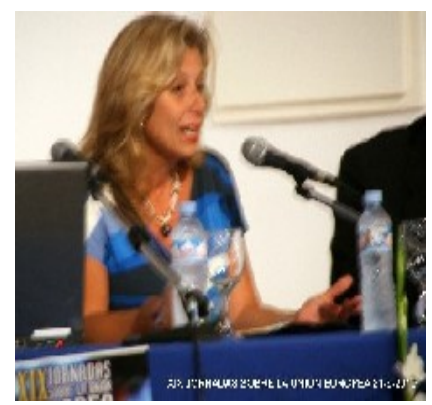

Dra. Marycruz Arcos Vargas

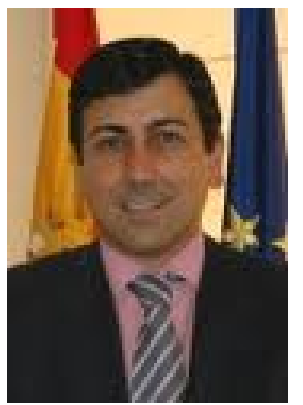

D. Luis Nieto Ballesteros

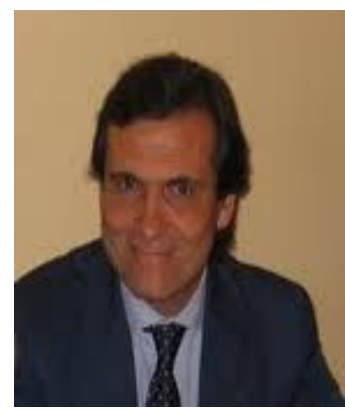

Dr. Luis Palma Martos

Conferencia de Marycruz: "La crisis de la deuda soberana. 2010". XX Jornadas sobre la Unión Europea: "La Respuesta de la Unión Europea a la crisis"17.

Y analizando las aportaciones de Ma Cruz a la Universidad y a la Sociedad Internacional, nos preguntamos por la bondad del sistema de promoción universitaria. Y le pedimos su opinión: ¿Qué te parece el sistema actual de un baremo, un instrumento cuantitativo, y unos requisitos "objetivos" universales para poder promocionar, de forma que alguien que verdaderamente tiene algo que decir y que aprende cada día de las más diversas situaciones en las que se implica, no solicite la acreditación porque nadie va a estudiar a fondo el valor real que hay detrás de la cantidad?

Es el problema de mi cátedra. Efectivamente yo debía ser más pragmática, más organizada, y debía decir: cada cosa en su momento, porque voy a cumplir 50 años (al año que viene) y como no me siente, no lo voy a hacer en la vida. Ahora ¿a mí me merece la pena dejar todo lo que estoy haciendo ahora mismo para lograr los sexenios, tengo que dejar... para publicar en ciertas revistas, que podría estar publicando porque de hecho, cuando hago algo a la gente le gusta mucho, por ejemplo, el libro de Tecnos, o un artículo sobre "procedimientos de decisión", que es una cosa muy técnica, muy específica, y que está teniendo mucha aceptación, y que está teniendo mucho éxito..., pero no merece la pena dejar la actividad. Bueno, el Máster de estudios europeos, que es el que tenemos ahora mismo, que está en su tercera edición... pues me divierte mucho, y me entretengo mucho con él, porque no es sólo dar las clases, es la tutorización de las prácticas externas, que es algo bien complejo y que nos vuelve locos, pero es bien interesante; pero no sólo, es el trabajo de fin de Máster, que con cada trabajo yo aprendo una barbaridad, porque yo me presto a dirigirles los temas más diversos, trabajos en los que te implicas... siempre que tenga un cierto fundamento para poder entender; desde temas sobre las misiones de paz de la Unión Europea, a otro interesantísimo sobre la política pesquera y el acuerdo con Marruecos, y, bueno, vamos descubriendo temas, y eso da mucho trabajo...

\section{Un guiño a las mujeres: ¿Cuál es su aportación a la igualdad en el mundo universitario?}

Sin duda, la autovaloración, considerando que debe hacer y poner en práctica lo que sabe, por lo tanto desempeñar los puestos para los que está preparada y quizá nadie

\footnotetext{
${ }^{17}$ http://www.sodemar.eu/web/modules/smartsection/item.php?itemid=1431
} 
más puede ejercer con éxito en un momento dado. Ejercer el poder sin "la plena investidura" del poder, como ha dicho Celia Amorós, pero con la investidura del conocimiento y la capacidad. Meterse en todos los charcos por gusto, por demanda institucional y por saberse competente. Saber que aprovechar oportunidades siempre significa elección, que conlleva trabajo, tiempo, disfrutar de ello y perderse otras oportunidades, a las que el interés personal la orientaría, porque una mujer profesional cuando piensa su carrera no está sólo ella en el horizonte. Y creer en la capacidad de aprendizaje y desarrollo personal y profesional mientras se desempeñan funciones institucionales:

Mi progreso profesional se debe a que he sabido aprovechar oportunidades: he ido cogiendo trenes y he descubierto mis capacidades de organización, de relación, de comunicación".

Son capacidades transversales, necesarias para el ejercicio de las funciones organizativas y docentes. De liderazgo educativo, institucional y social. Pero, es posible que ello vaya en detrimento de su personal progreso profesional administrativo. Aunque la Agencia de la Competencia, le reconozca el valor del conocimiento universitario, su competencia. Dirige una Cátedra respondiendo a demandas externas, pero no es Catedrática.

Ya para terminar,
quisimos hacerle una
pregunta global: ¿Qué es lo
que más te gusta de la
Universidad? Su respuesta
fue rotunda y esponjada,
con esa sonrisa amplia y
segura que contagia su
alegría:

Los alumnos.

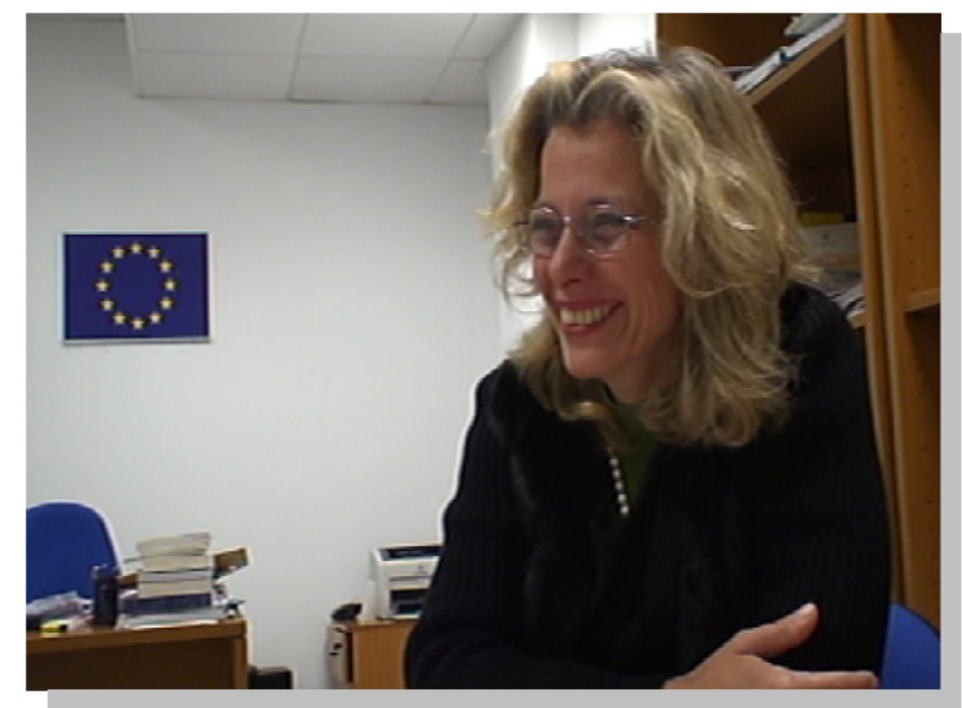

Cita del artículo:

Estebaranz García, A.; Ballesteros Moscosio, M.A. (2012). Internacionalización de la universidad: abrir ventanas al conocimiento $\mathrm{y}$ al mundo profesional. Revista de Docencia Universitaria. REDU. Monográfico: Buenas prácticas docente en la enseñanza universitaria. 10 (1), 477-513. Recuperado el (fecha de consulta) en http://redaberta.usc.es/redu 


\section{Acerca de la autora y el autor}

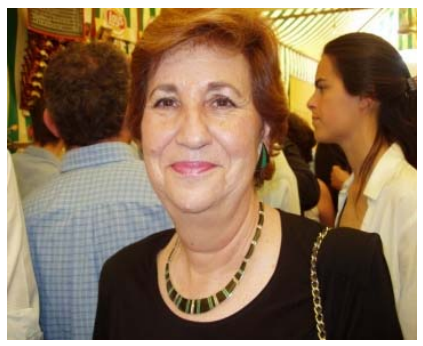

\section{Araceli Estebaranz García}

\section{Universidad de Sevilla}

Facultad de Ciencias de la Educación

Departamento de Didáctica y Organización Escolar

Mail: tebaranz@us.es

Catedrática de Didáctica y Organización Escolar de la Universidad de Sevilla. Ha investigado, enseñado y publicado sobre temas de enseñanza, currículum, innovación y formación del profesorado en los distintos niveles de enseñanza. En los últimos 12 años centra el trabajo de investigación y formación en la Igualdad/Desigualdad de mujeres y hombres en el mundo profesional. Coordinó los estudios que realizó un equipo interdisciplinar de la Universidad de Sevilla dentro de los Proyectos EQUAL, financiados por el Fondo Social Europeo: Observatorio sobre Andaluzas que abren caminos (2002-2004), que dio lugar a la publicación de 80 historias de vida de mujeres de alta categoría profesional de diferentes sectores y áreas, y Barómetro de la Diversidad de género en el empleo (2005-2007), cuyos resultados han sido presentados en diversos foros y publicaciones: Libros, revistas y actas de Congresos.

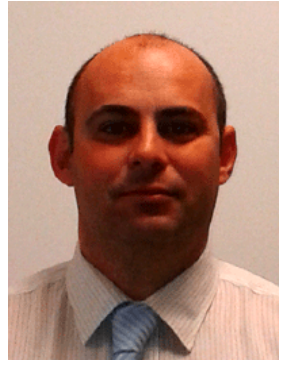

\section{Miguel Ángel Ballesteros Moscosio}

\section{Universidad de Sevilla}

Facultad de Ciencias de la Educación

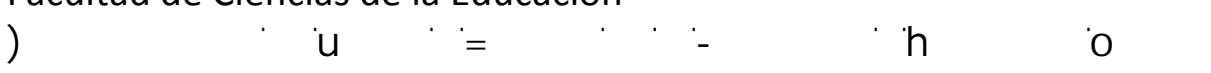
Mail: $\underline{\text { miguelanba@us.es }}$

Profesor Ayudante del Departamento de Teoría e Historia de la Educación y Pedagogía Social de la Universidad de Sevilla. Experto en Nuevas Tecnologías para el aprendizaje a través de Internet por la Universidad de Sevilla. Ha sido miembro del equipo de evaluación e investigación de los Proyectos EQUAL Andalucía en e-lgualdad (20022004) y Barómetro de la Igualdad de Género en el Empleo (2005-2007). Sobre el primero de ellos desarrolló su tesis doctoral titulada "Redes de aprendizaje para la construcción cultural de Europa: Análisis del proyecto Andalucía en e-lgualdad". También ha participado en los proyectos "Access and Retention: The experiences of non-traditional students in Higher Education - RANLHE" (135230-LLP-1-2007-1-UK-KA1 SCR) y "Career Counselling for teachers -CCT" (Comenius, 1999), así como en redes profesionales internacionales como la Trainer Teacher Net (TTnet). Actualmente forma parte del equipo de investigación del proyecto I+D+i "Análisis del modelo formativo del profesorado de Educación Secundaria: Detección de necesidades y propuestas de mejora" (EDU2011-28946). Su interés como investigador se centra en el estudio de los procesos de gestión del conocimiento y de desarrollo del capital humano, el aprendizaje, la innovación social, las redes y el uso de las TIC como mediadores culturales para la formación, tanto en la empresa como en el ámbito escolar y universitario. 
